\title{
استخدام أسلوب اندار الحرف لتقدير حجم الهجرة الداخلية لجمهورية مصر العربية
}

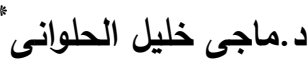

\section{موجز}

يهدف البحث لتوضيح كيفية استخدام أسلوب انحدار الحرف Ridge Regression ، في دراسة تأثير بعض العوامل على الهجرة الداخلية لجمهورية مصر العربية، وذلك بتحليل البيانات الخاصة بالهجرة الداخلية في جمهورية مصر العربية للفترة (1996-2015) • وقد تم باستخدام البرنامج الإحصائي الجاهز NCSS الحصول على النتائج التي تخص هذه الدراسة . وقد تمت المقارنة بين أساليب مختلفة من طرق الانحدار المتعدد المستخدمة في هذا البحث، والمتمثلة في طريقة المربعات الصغرى العادية "OLS"، وأسلوب انحدار الحرف Ridge Regression ، وذللك بقياس جودة النماذج المتحصل عليها من كل طريقة باستخدام معايير الجودة، المتمثلة في متوسط مربع الخطأ (MSE)، وكذلك باستخدام

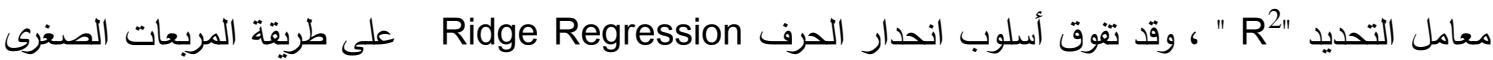
العادية "OLS" وفقًا للمعايير الإحصائية المستخدمة.

\section{Using Ridge Regression Method to Estimate}

the Internal Migration Rates in Egypt

\section{Abstract}

This research aims to illustrate the usage of the Ridge Regression Method to study the effect of some factors on the internal migration in the Arab Republic of Egypt, by analyzing data of internal migration for the period (1996-2015) . The results of this study were obtained using the statistical program - NCSS.

The comparison between two different regression models used in the research, (the normal least squares method "OLS" and the method of Ridge Regression) was made using the criteria of (MSE) Mean Square Error and $\left(\mathrm{R}^{2}\right)$ coefficient of determination. The statistical criteria used showed that, the Ridge Regression Method has outperformed the normal least squares method "OLS".

$$
\text { * قسم الإحصاء والرياضة ، كلية التجارة ، جامعة عين شمس. }
$$


تعد الهجرة أحد العناصر الثلاثة المسئولة عن التغير السكاني في مجتمع ما، وهي الخصوبة والوفيات والهجرة. وتختلف الهجرة عن العنصرين الآخرين من عدة جوانب. فعلى العكس من كل من الخصوبة والوفيات، اللتين يسهل جمع بيانات عنهما ومن ثم قياسهما بشكل دقيق، فإن الهجرة يصعب قياسها بمثل تلك الدرجة من الدقة، لأن تدفق المهاجرين لا يتسم بالثبات من الناحية الزمنية،

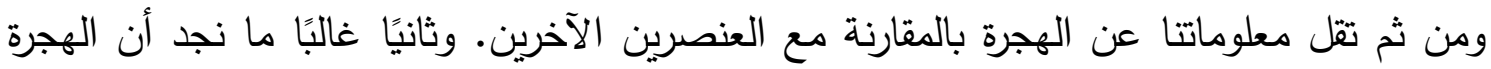
تكون موضع رقابة قوية من جانب الدول، للسيطرة عليها بالمقارنة مع كل من الخصوبة والوفيات.

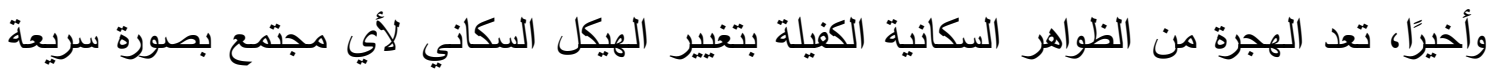

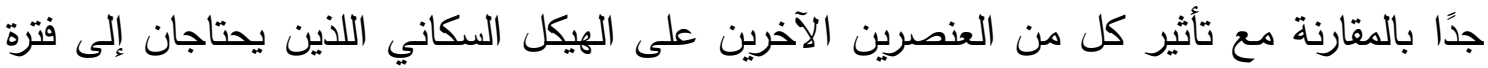
طويلة جدًا من الزمن لكي تؤدي إلى تغييره. وتُعد الهجرة أصعب الظواهر الديموجرافية من حيث القيثرة القياس أو من حيث مدى توافر



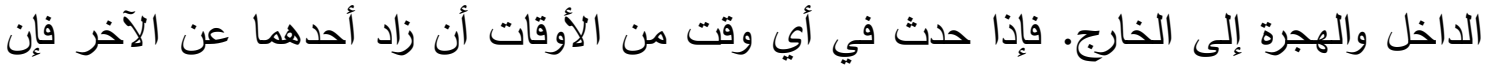
ذللك يؤدي إلى إحداث آثار مختلفة على النمو السكاني في المنطقة، حيث إن التغات التير السكاني

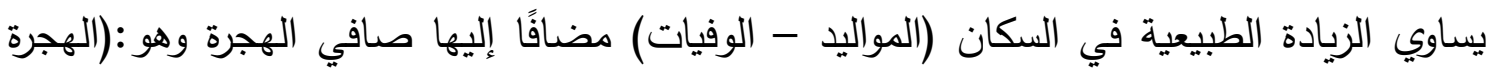

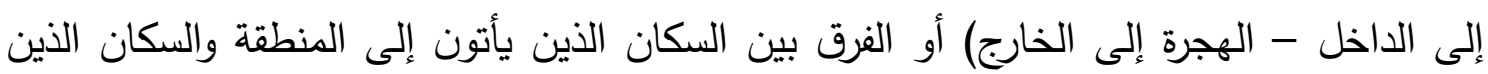
يغادرونها.

فمن المعلوم أن التغير السكانى في منطقة ما يحسب من خلال المعادلة الديموجرافية

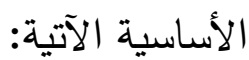

$$
\mathrm{P}_{\mathrm{t}}-\mathrm{P}_{\mathrm{t}-1}=(\mathrm{B}-\mathrm{D})+(\mathrm{I}-\mathrm{O})
$$

$$
\text { حيث إن: }
$$

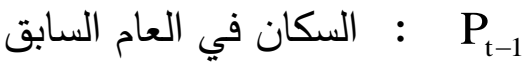

$$
\begin{aligned}
& \text { t : : : : } \\
& \text { D } \\
& \text { B : B } \\
& \text { O } \\
& \text { I }
\end{aligned}
$$


بمعنى آخر، أن التغير السكاني يساوي الزيادة الطبيعية في السكان (B - D) مضافًا إليها

صافي الهجرة (O - I)، أو الفرق بين السكان الذين يأتون إلى المنطقة والسكان الذين يغادرونها. وعادة ما يتم تقدير الهجرة باستخدام ما يسمى بأسلوب البواقي، وذلك من خلا حل المعادلة الديموجرافية الأساسية بالنسبة لصافي الهجرة أي أن:

$$
(\mathrm{I}-\mathrm{O})=\left(\mathrm{P}_{\mathrm{t}}-\mathrm{P}_{\mathrm{t}-1}\right)-(\mathrm{B}-\mathrm{D})
$$

أي أنه إذا تم طرح صافي الزيادة الطبيعية للسكان من التغير الذي يحدث في عدد السكان

$$
\text { فإن الباقي يكون التغير في أعداد السكان الراجع إلى الهجرة،( جدول رقم 1). }
$$

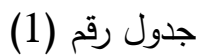

\begin{tabular}{|c|c|c|c|c|c|c|c|}
\hline year & 1 & $\mathrm{P}$ & $\left(P_{t}-P_{t-1}\right)$ & B & D & $(B-D)$ & 0 \\
\hline 1993 & & 59230000 & 0 & 1601 & 380 & 1221 & 831 \\
\hline 1994 & 1309846 & 60540000 & 1310000 & 1611 & 385 & 1226 & 1072 \\
\hline 1995 & -3029374 & 57509998 & -3030002 & 1605 & 385 & 1220 & 1848 \\
\hline 1996 & 1245184 & 58755211 & 1245213 & 1662 & 380 & 1282 & 1253 \\
\hline 1997 & 1324586 & 60080063 & 1324852 & 1655 & 389 & 1266 & 1000 \\
\hline 1998 & 1260414 & 61340882 & 1260819 & 1687 & 400 & 1287 & 882 \\
\hline 1999 & 1297408 & 62638849 & 1297967 & 1693 & 401 & 1292 & 733 \\
\hline 2000 & 1335118 & 63974724 & 1335875 & 1752 & 405 & 1347 & 590 \\
\hline 2001 & 1322997 & 65298293 & 1323569 & 1741 & 405 & 1336 & 764 \\
\hline 2002 & 1328655 & 66627610 & 1329317 & 1767 & 424 & 1343 & 681 \\
\hline 2003 & 1336459 & 67965096 & 1337486 & 1777 & 440 & 1337 & 310 \\
\hline 2004 & 1364366 & 69330423 & 1365327 & 1780 & 441 & 1339 & 378 \\
\hline 2005 & 1322009 & 70653326 & 1322903 & 1801 & 451 & 1350 & 456 \\
\hline 2006 & 1354569 & 72008901 & 1355575 & 1854 & 452 & 1402 & 396 \\
\hline 2007 & 1633574 & 73643587 & 1634686 & 1950 & 451 & 1499 & 387 \\
\hline 2008 & 1548811 & 75193567 & 1549980 & 2051 & 462 & 1589 & 420 \\
\hline 2009 & 1730110 & 76925139 & 1731572 & 2217 & 477 & 1741 & 279 \\
\hline 2010 & 1758322 & 78684622 & 1759483 & 2261 & 483 & 1778 & 617 \\
\hline 2011 & 1843955 & 80530000 & 1845378 & 2442 & 493 & 1949 & 526 \\
\hline 2012 & 1773410 & 82305000 & 1775000 & 2630 & 530 & 2100 & 510 \\
\hline 2013 & 2322319 & 84629000 & 2324000 & 2622 & 511 & 2111 & 430 \\
\hline 2014 & 2183318 & 86814000 & 2185000 & 2720 & 532 & 2187 & 505 \\
\hline 2015 & 2142430 & 88958000 & 2144000 & 2685 & 574 & 2111 & 541 \\
\hline
\end{tabular}

حساب سلسلة زمنية للهجرة الداخلية بطريقة غير مباشرة

وفيما يلي نتناول بعض مقاييس الهجرة: 


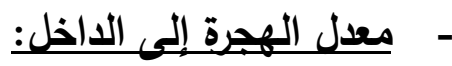

يقيس معدل الهجرة إلى الداخل النسبة بين عدد المهاجرين إلى داخل المنطقة وعدد سكان

تللك المنطقة كالآتي:

$$
\text { معدل الهجرة إلى الداخل = } 1000 \text { × }
$$

أي أنه يوضح عدد المهاجرين إلى داخل منطقة معينة مقابل كل ألف من عدد السكان في

تللك المنطقة.

\section{- - معدل الهجرة إلى الخارج: -}

يقيس معدل الهجرة إلى الخارج النسبة بين عدد المهاجرين إلى خارج المنطقة وعدد السكان

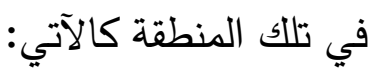

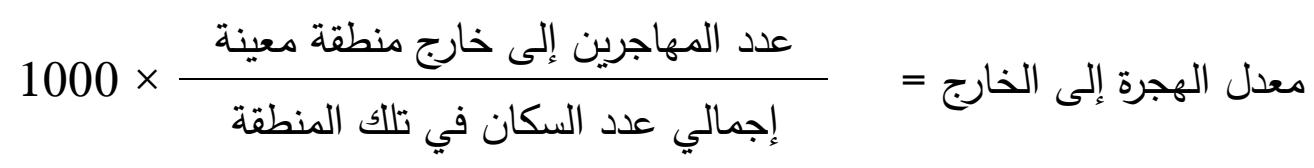

أي أنه يوضح عدد المهاجرين إلى خارج المنطقة مقابل كل ألف من عدد سكان تلك المنطقة.

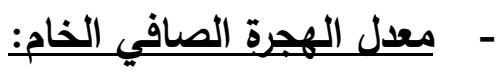

يقيس معدل الهجرة الصافي الخام صافي أعداد المهاجرين في سنة ما لكل ألف شخص من السكان ونطلق عليه صافي معدل الهجرة؛ لأنه يقيس الفرق بين أعداد المهاجرين إلى الداخل وأعداد

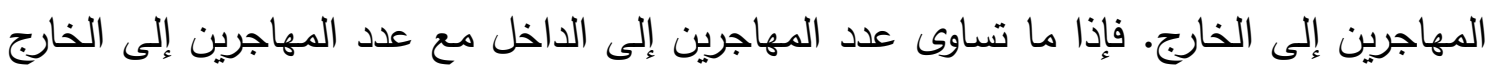

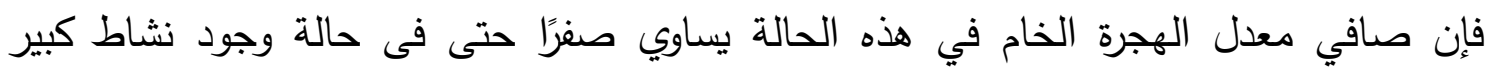
للمهاجرين إلى الداخل والخارج. معدل الهجرة الصافي الخام= وهو يوضح صافي معدل الهجرة الخام لكل ألف من عدد السكان. 


\section{- معدل الهجرة:}

يعبر معدل الهجرة عن مدى مساهمة الهجرة في النمو السكاني للمنطقة أو الدولة ويقاس

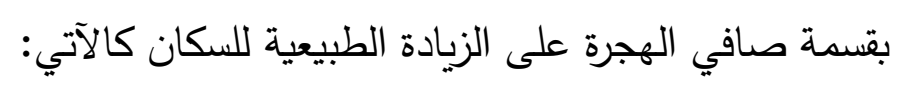

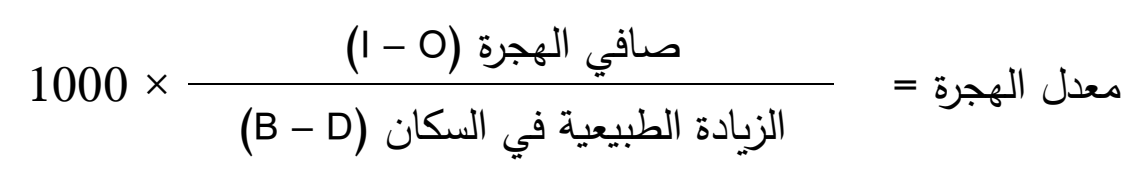

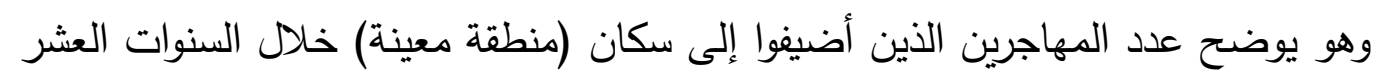
(الفرق بين التعدادين) لكل ألف من السكان الذين أضيفوا من خلال الزيادة الطبيعية. أولاً : الإطرا العام للبحث: 1

\section{1-1}

الهجرة هي أن يترك شخص أو جماعة من الناس مكان إقامتهم لينتقلوا للعيش في مكان آخر، ذلك آلك

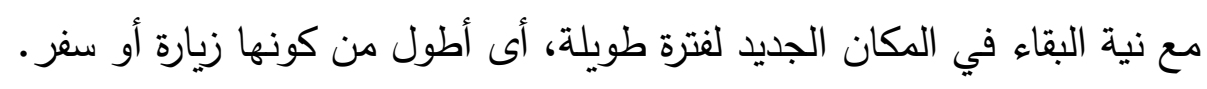
كما يقصد بالهجرة انتقال الأفراد من منطقة ما إلى منطقة أخرى. سواء كان ذلك داخل

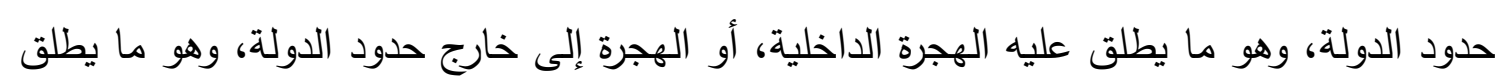

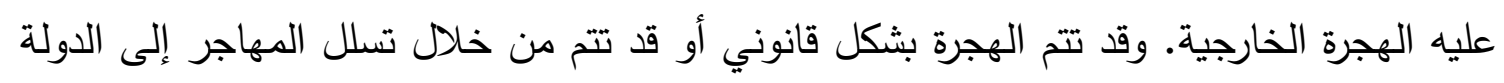

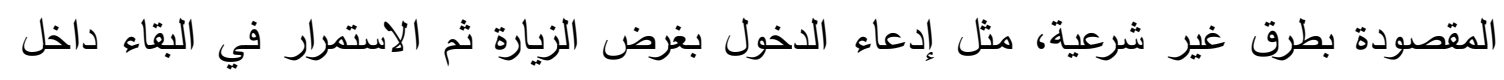





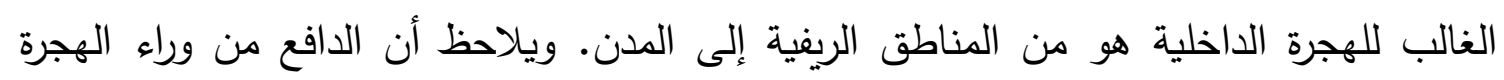

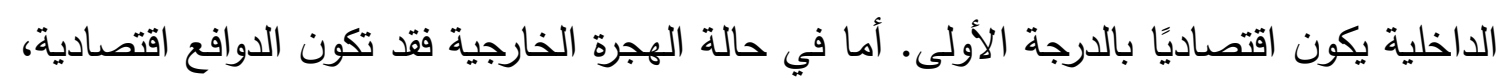

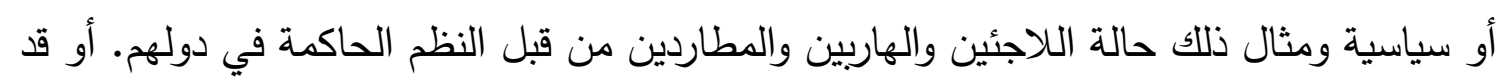

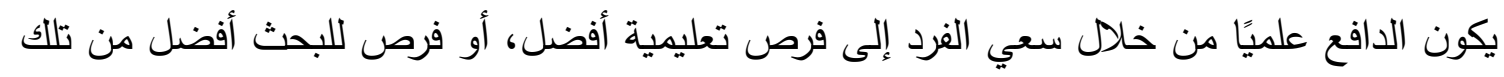

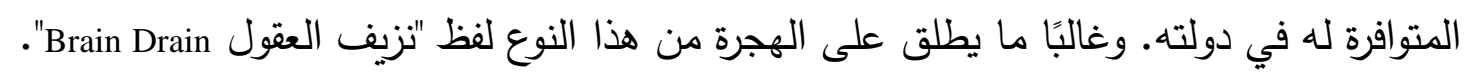


أما عن البعد الزمني للهجرة، فقد تتم الهجرة بشكل مؤقت وذللك حينما ينوي المهاجر الإقامة في المهجر لمدة مؤقتة ثم العودة مرة أخرى إلى الوطن، أو قد تكون الهجرة دائمة حينما لا ينوي المهاجر العودة مرة أخرى إلى بلده الأصلي. وتبدو هناك صعوبة كبيرة من الناحية الإحصائية في تعريف المقصود بالمهاجر، ولذلك اتفق الديموجرافيون على أن المهاجر هو الثخص الذي يقيم بشكل مستمر في دولة أخرى أو في إقليم آخر، أو الذي يعلن عندما يعبر الحدود عن نيته في البقاء لمدة أكثر من سنة.

\section{1-2-1 - لماذا يهاجر السكان؟}

تُعد نظرية عوامل الجذب وعوامل الطرد من أكثر النظريات شيوعًا في تحليل الأسباب التي تدفع بالأفراد إلى الهجرة، وتقوم النظرية ببساطة على فكرة أن الناس يهاجرون لأن هناك عوامل طاردة لهم من موطنهم الأصلي، أو أن هناك عوامل جاذبة لهم في المنطقة المضيفة. وقد وضع فكرة هذه النظرية رافنشتاين عام 1889 الذي قام بتحليل بيانات الهجرة في انجلترا وويلز، واستنتج أن عوامل الجذب عادة ما تكون أكثر أهمية من عوامل الطرد في تحديد قرار الهجرة. إذ أن الرغبة في تحسين المستوى المادي للفرد تكون أقوى من الرغبة في الهروب من وضع سيء في الموطن

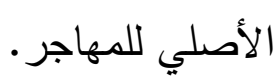

ومما لا شك فيه أن مجرد وجود العوامل الطاردة في الموطن الأصلي لن يدفع بالفرد إلى الهجرة إلا إذا كان لديه علم بأن هناك فرص أفضل في مكان آخر. على أساس أن إقدام المهاجر على الهجرة يعتمد على عملية حساب للتكلفة والعائد من عملية الهجرة حيث أنه يقوم بوزن عوامل الجذب والطرد ثم يتخذ القرار بالهجرة إذا كانت المنافع التى تؤدي إليها عملية الهجرة تتعدى التكلفة المتصلة بها. على سبيل المثال يتضمن قرار المهاجر بترك وظيفته، ومكانته في العمل لإنتهاز فرصة وظيفة أفضل في البلد المضيف عملية مقارنة بين العائد الذي يحصل عليه من الوظيفة الجديدة، والمكانة الأعلى في العمل، وبين التكلفة التي يتحملها بانتزاع نفسه وأسرته من موطنه الأصلي، وترك منزله ومجتمعه الذي اعتاد الحياة فيه، وأصدقائه الذين اعتاد وجوده بينهم. ومن الناحية الواقعية لا يأتي قرار المهاجر بالهجرة فجأة، وإنما يتم على مدى فترة زمنية طويلة نسبيًا، 
تبدأ من ظهور الرغبة لدى المهاجر فى الهجرة، والوقت الذي يتوقع أن يهاجر فيه. وأخيرًا التوقيت

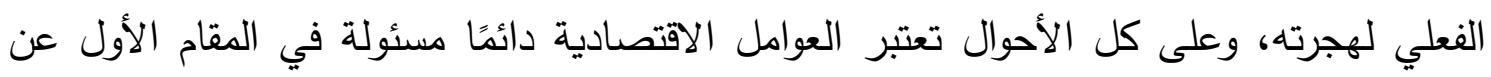

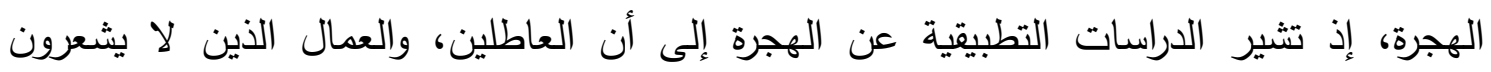
بالرضاء عن وظائفهم، هم غالبًا الذين يميلون للهجرة.

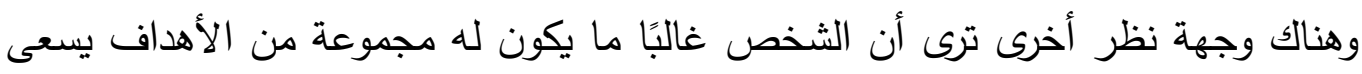

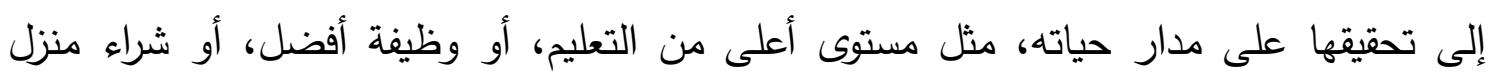

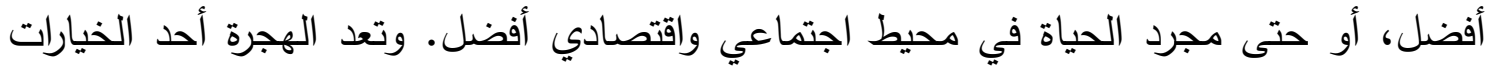

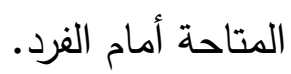

ومن ناحية أخرى توضح الدراسات أن عامل المسافة بين الريف والحضر على وجه

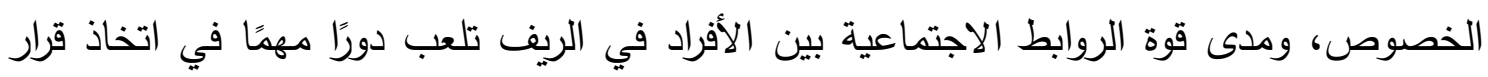

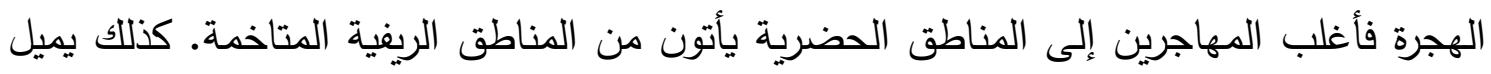

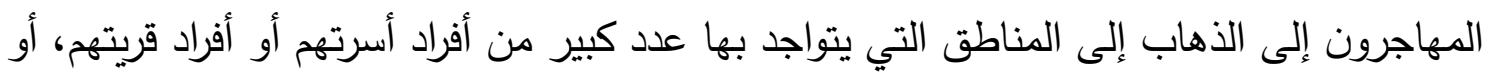

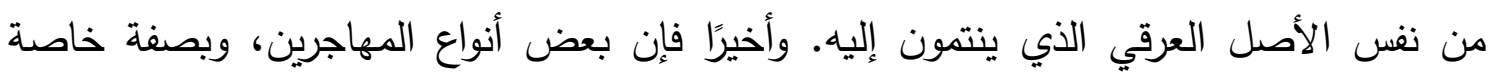
الشباب، عادة ما ينجذبون بأضواء المدينة الباهرة.

1 - 1 تكلفة الهجرة:

يوضح هاريس وتودارو (Harris \& Todaro) في نموذجهما للهجرة الداخلية من الريف إلى لئ

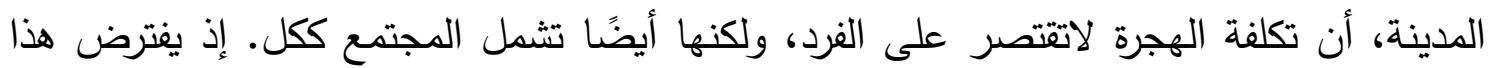
النموذج أن هناك تسابقًا من جانب المهاجرين على الوظائف التي يتم خلقها في الددن. ففي مقابل

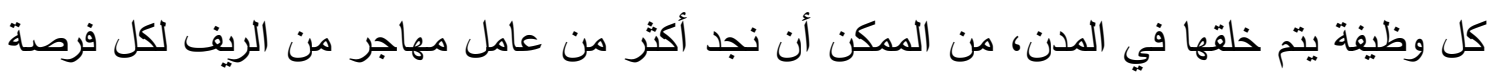

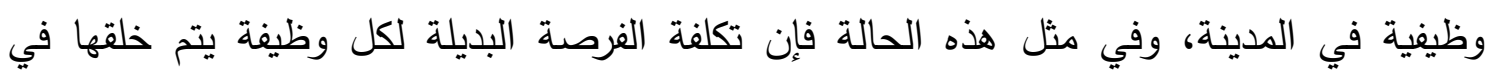
المدينة، تكون فقدان هذه المنطقة الريفية لما كان يحققه العامل المهاجر من انتاج لها. وقد لانه لانه

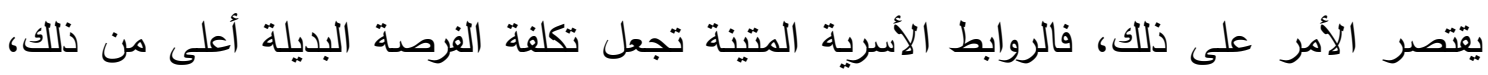

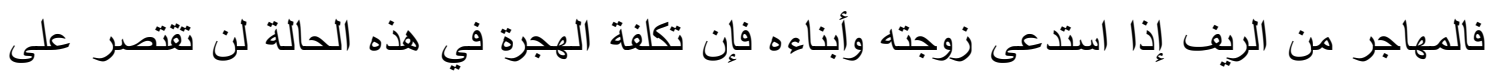

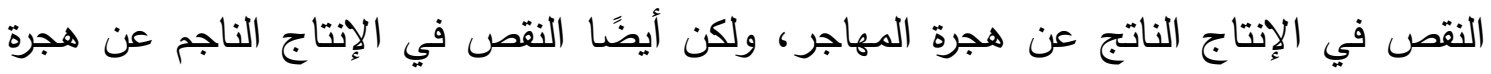


الزوجة والأطفال الذين غالبًا ما يعملون في الأرض. وبالإضافة إلى النقص في الإنتاج فإن

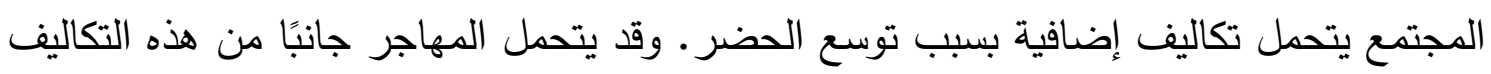

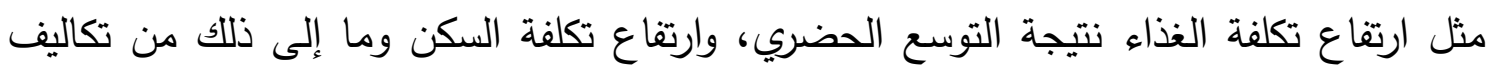

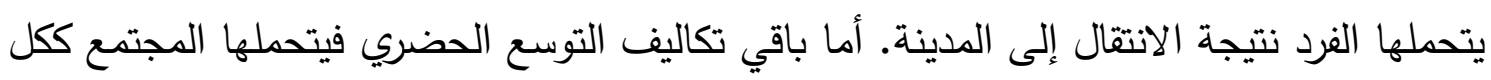

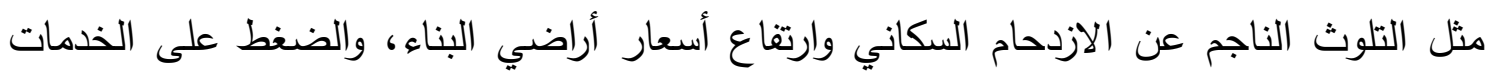

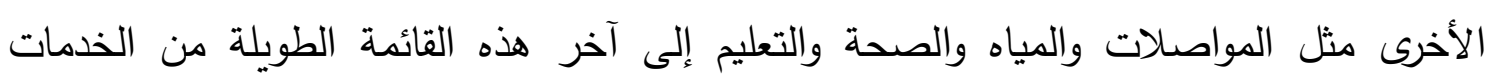

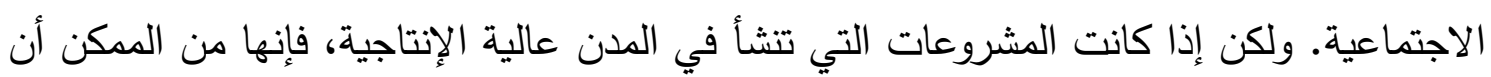

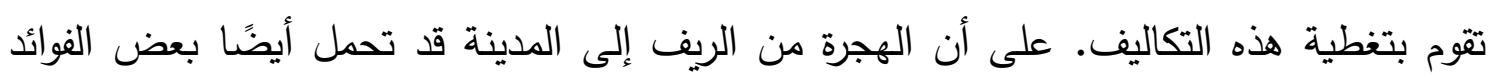

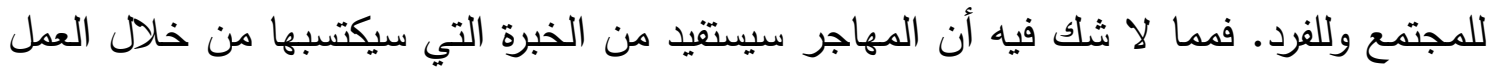
والتدريب في القطاع الحضري من المجتمع. 4-1 الفرق بين الهجرة الداخلية والهجرة الخارجية: تتميز الهجرة الداخلية بالحرية، بمعنى أن قرار الانتقال من مكان لآخر داخل الآل حدود الدولة



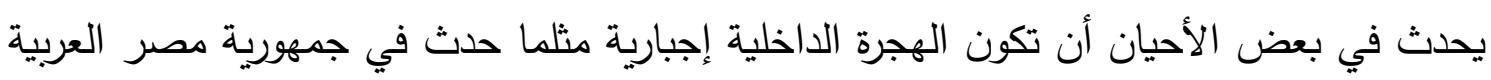

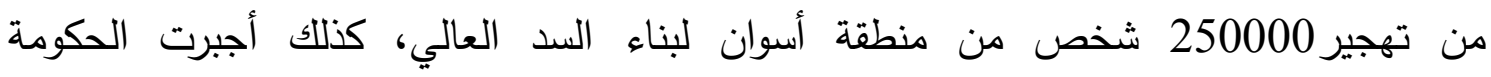
الإندونيسية الكثير من سكان جزيرة جاوة إلى الهجرة إلى الجزر الأخرى الأقل كثافة، ومثل هذهاه

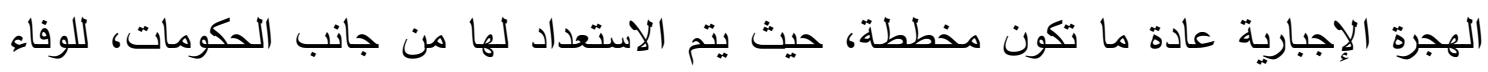

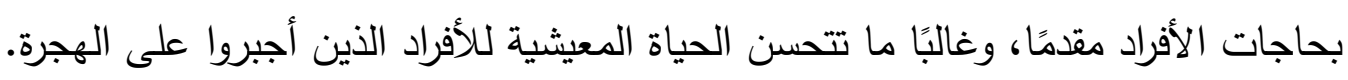

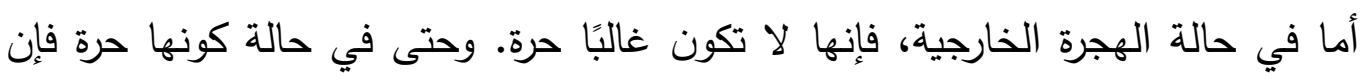

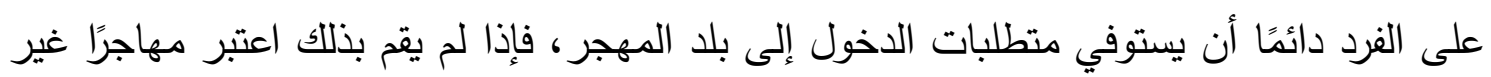

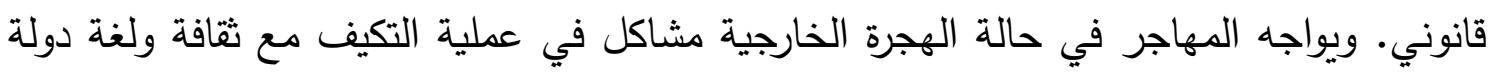

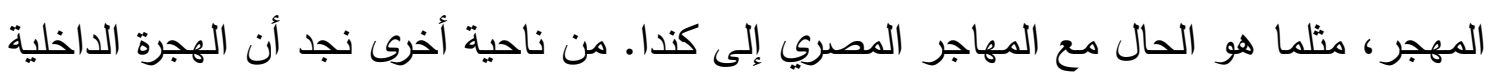

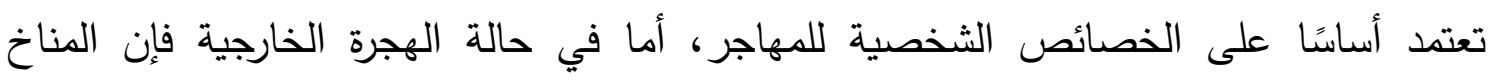
الاجتماعي والسياسي وهيكل الفرص المتاحة في بلد المهر تلعب دورًا أساسيًا في اتخاذ القرار 
بالهجرة. وأخيرًا فإن طبيعة الأهداف التي يسعى إليها المهاجر قد تختلف في حالة الهجرة الخارجية عنها فى حالة الهجرة الداخلية. وتُعد ظاهرة الهجرة الداخلية في جمهورية مصر العربية من الظواهر الديموجرافية الواجب دراستها بعناية واهتمام، لأنها ترتكز على عدة عوامل اقتصادية واجتماعية من جهة، ولأنها تؤدي إلى حدوث تغيرات كثيرة، سواء في التركيب العمري والنوعي للسكان، كما تؤدى الهجرة الداخلية إلى اختلال التوزيع المكانى للسكان، وهو أحد أهم المشاكل الديموجرافية فى مصر .

5-1 للهجرة أنواع متعددة تختلف فيما بينها باختلاف المبدأ أو الأساس المعتمد في تصنيفها، ولكن يمكن اعتماد المبادئ الآتية في تحديد أنواع الهجرة: أ- الحدود الدولية: وعندها يمكن التمييز بين الهجرة الداخلية والهجرة الخارجية. ب- طبيعة قرار الهجرة: وهنا يمكن التمييز بين: - هجرة اختيارية: يقررها المهاجر بمحض إرادته دون تأثير أو ضغط يدفعه إليها. - - هجرة قسرية: يهاجر الفرد أو الجماعة بموجبها وهم مكرهون عليها كتلك الناتجة عن لن الحروب أو المجاعات، وأيضًا عن الأزمات أو الكوارث الطبيعية. ت- البُعد الزمني ومدة الهجرة حيث يمكن التمييز بين: هجرة دائمة ، هجرة مؤقتة ، وهجرة موسمية. ونظرًا لأن الموضوع الذي يدور حوله البحث هو الهجرة الداخلية، فإننا نرى أن نوضح أولاً


بدورها أوجه التباين بين هذين النوعين من الهجرة من حيث الدوافع والآثار الناجمة عنها، ويمكن إيجازها بالنقاط الثلاث الآتية: أ- الهجرة الداخلية أقل تكلفة من الهجرة الخارجية بحكم أن الحركة تتم لمسافة قصيرة وداخل البلد الواحد، وتدفع تكاليفها بوحدات النقد المحلي. ب- الهجرة الداخلية لا تحتاج إلى إجراءات مغادرة ودخول (كالحصول على تأثيرات خروج ودخول ... إلخ) كما هو الحال في الهجرة الخارجية التي هي نقلة من بلد إلى آخر . 
ت- الاستعداد النفسي والتأقلم في الهجرة الداخلية يكون أسرع بكثير مما فى الهجرة الخارجية (مشكلة اللغة، العادات والتقاليد، ... إلخ).

وللهجرة الداخلية أنواع متعددة مثل: هجرة من الريف إلى الحضر ، وهجرة من الحضر إلى لـ الريف وهجرة من الحضر إلى الحضر (من منطقة إدارية إلى منطقة إدارية أخرى)، وهجرة من الريف إلى الريف (هجرة من مزرعة لأخرى). وتُعد الهجرة الريفية الحضرية اليوم من أهم مظاهر حركة السكان في الدول النامية، خاصة الدول العربية، التي مازالت نسبة سكان الريف فيها مرتفعة ويرجع هذا النوع من الهجرة إلى كل من عوامل الطرد (أو الدفع) في المناطق الريفية وعوامل الجذب في المناطق الحضرية. وهناك عوامل كثيرة تقف وراء الهجرة، ولكن تظل أهمها المحفزات (العوامل) الاقتصادية كتلك المتعلقة بالدخل أو المهنة ومصدر كسب الرزق، أو بالفقر والحرمان وعدم وجود مشاريع أو أملاك يستطيع الفرد أن يحصل بواسطتها على مقومات العيش الذي يطمح إليه، ثم الضغط السكاني، والكثافة السكانية والخلافات العشائرية والعائلية والطائفية، أو تسلط الأهل وانعدام العدالة الاجتماعية، وتضائل الفرص الاقتصادية، وندرة الخدمات والمرافق، وانخفاض الإنتاج الزراعي الذي يسبب الفقر والجوع، وافتقار المناطق الريفية للاستثمارات الصناعية والخدمات الاجتماعية والصحية والتعليمية والثقافية، كذلك فإن حدوث الكوارث والحروب، وتعاقب حدوث الجفاف والفيضانات كلها تمثل عوامل طرد تدفع الريفيين للهجرة إلى المناطق الحضرية. وفي الجانب الآخر تمتاز المدن بكثير من عوامل الجذب مثل توافر فرص العمل فيها، وارتفاع دخول سكانها، كما أنها تتيح التعليم والثقافة، والنقل والمواصلات والخدمات الاجتماعية مما أدى إلى اتساع الفجوة التتموية بين الريف والحضر بالرغم من تقدم وسائل النقل التي ساهمت إلى وداء ولى حد كبير في التخفيف من العزلة الريفية. ويعتبر المواطن المصري من أوائل الذين مارسوا الهجرة من الريف إلى الحضر من قديم. فقد كان المهاجرون يأتون من المناطق الريفية كثيفة السكان، مثلما حدث في محافظات المنوفية، وأسوان، والقليوبية، وأسيوط، وجرجا، وسوهاج، وقنا، إلى كل محافظات مصر خاصة القاهرة والإسكندرية، حتى وصلت الكثافة السكانية في المدن إلى (10000) نسمة في الكيلو متر المربع، 
في حين وصلت كثافة الريف السكانية إلى (600) نسمة في الكيلو متر المربع، وانخفضت نسبة سكان الريف من (82.8\%) تعداد 1907 إلى (57.36\%) تعداد 1996 كما ارتفعت نسبة سكان

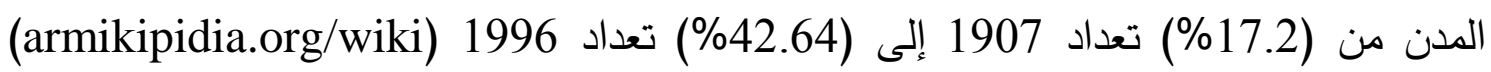
واستمر تيار الهجرة الداخلية إلى أن وصل إلى 16 1973,482 مهاجر حسب تعداد 2006 (الكتاب الإحصائي السنوي 2016). ونظرًا لخطورة هذه الظاهرة على الريف الذي ظل فترة طويلة على هامش اهتمامات الدولة،

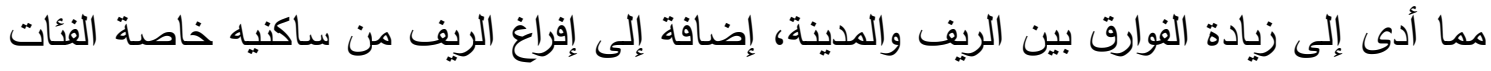

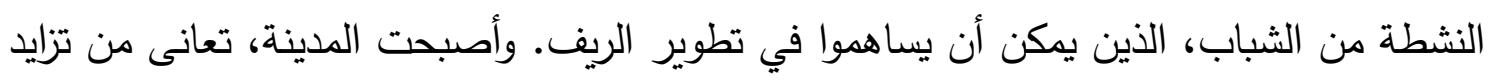
كبير في عدد سكانها، مما خلق مشاكل واختلالاً في مستوى المعيشة بسبب زئن زيادة الكثافة السكانية. فقد ظهرت بيوت الصفيح وانتشرت العشوائيات والبنايات غير المرخصة، ولتئ وانتشرت الجريمة نتيجة تفاقم البطالة وتردي مستوى الخدمات في الحضر . لتون ونظرًا لكل ما سبق يتطلب الأمر إلقاء الضودي ملى لفى هذه المشكلة التي أصبحت سمة من

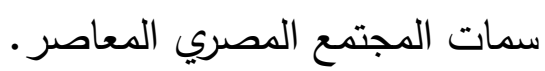
ونظرًا لقلة الدراسات والبحوث الحديثة في هذا الدجال فإنه يجب توجيه جهود الباحثين إليه، فهذا

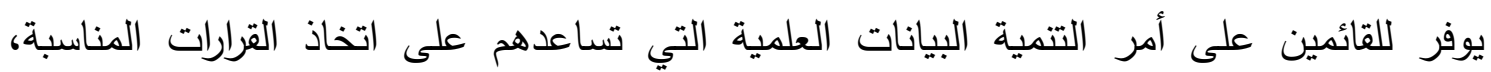
والتخطيط السليم للتمية في الحاضر والمستقبل، حتى يتسنى لواضعي السياسات والبرامج التتموية وضع الاستراتيجيات والخطط الكفيلة بتعديل هذا الاتجاه، وتتمية الاتجاه الإيجابي للثباب الريفي ولئي نحو الاستقرار بالريف لتطويره تلبية لاحتياجات التتمية. ويقسم التسلسل التاريخي لأنماط الهجرة الريفية الحضرية المصرية لإنية إلى ثلاث مراحل:

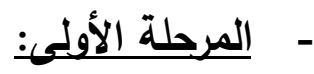

من أوائل القرن التاسع عشر وحتى بداية الخمسينيات، وكان المهاجرون في هذه المرحلة

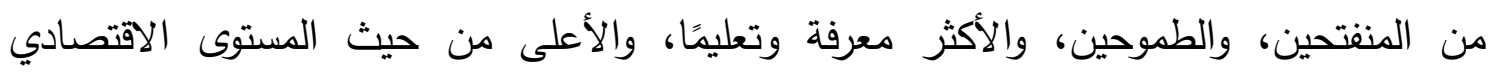

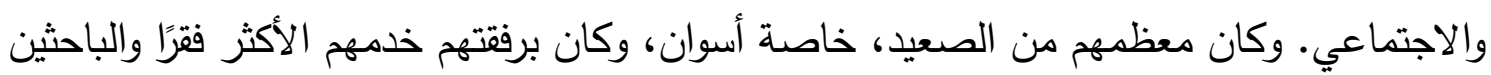
عن عمل. 


\section{-}

وهي فترة انطلاق الثورة وعصر التتمية والتصنيع النشط. و كان المهاجرون من الذين جاءوا للعمل في المصانع التي أنثأتها الثورة في القاهرة وحلوان، وهم الأكثر فقرًا والأقل تعليمًا وكانوا يقومون بالأعمال غير الماهرة والخدمية.

\section{-}

وهي مرحلة الانفتاح في منتصف السبعينات وحتى الآن (عصر العولمة) ويشبه

المهاجرون فيها المهاجرين في المرحلة الثانية بالإضافة إلى المهاجرين بدول الخليج والعراق والدول العربية الأخرى. وفي بداية الثمانينات ظهرت حركة عمران كبيرة في القاهرة شجعتها تحويلات العاملين بالخارج، إضافة إلى بناء الددن الجديدة مثل (السادس من أكتوبر والعاشر من رمضانه مما جذب أعدادا كبيرة من الريغيين إليها. وتؤثر الهجرة على كل من مكان الأصل، والوصول، والمهاجر نفسه. وقد تكون هذه الآثار

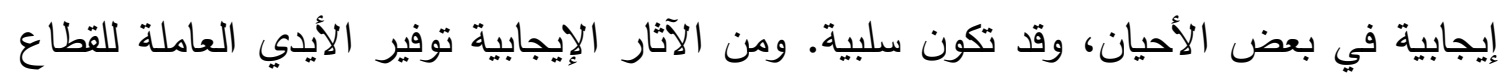
الصناعي مما يؤدي إلى تخفيف حدة البطالة، ورفع مستوى المعيشة من خلال مساعدة المهاجرين لأهلهم في الريف. ومن الآثار السلبية ارتفاع الكثافة السكانية في الددن مما أدى إلى. الضغط

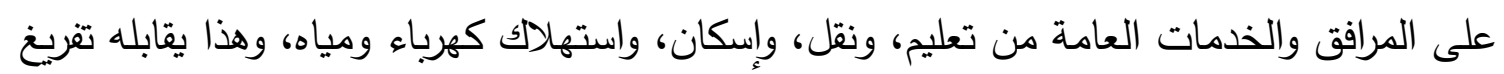
المناطق الريفية من سكانها.

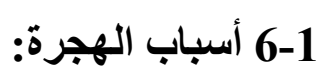
أ-اليهرة بسبب الانضمام إلى الأسرة (مرافق): يمثل هذا السبب المرتبة الأولى كما تؤكد البيانات، إذ أنه شكل سبيًا للهجرة لما نسبته

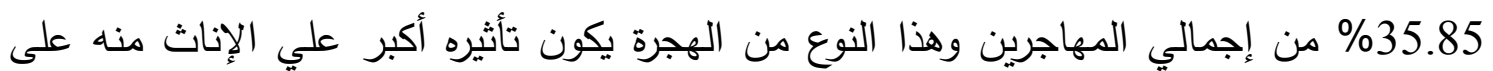


وتؤكد بيانات جدول رقم (2) أن نسبة المهاجرين تحت تأثير عامل مرافقة الأسرة (لم الثمل) كانت لاى الذكور منهم 27.5\% مقابل 62.5\% لدى الإناث. جدول رقم (2) (1)

حجم الهجرة الداخلية لـ ج•م·ع طبقا لسبب الهجرة والنوع

\begin{tabular}{|c|c|c|c|c|c|c|}
\hline \multicolumn{2}{|c|}{ إناث } & \multicolumn{2}{|c|}{ ذكور } & \multicolumn{2}{|c|}{ اجمالى } & \multirow{2}{*}{ بيـان } \\
\hline نسبة & عدد & نسبة & عدد & نسبة & عدد & \\
\hline $6.11 \%$ & 67687 & $93.89 \%$ & 1040194 & $23.21 \%$ & 1107881 & العمل \\
\hline $31.95 \%$ & 33847 & $68.05 \%$ & 72089 & $2.22 \%$ & 105936 & الدراسة \\
\hline $79.21 \%$ & 1088408 & $20.79 \%$ & 285722 & $28.79 \%$ & 1374130 & الزواج \\
\hline $85.55 \%$ & 26509 & $14.45 \%$ & 4477 & $0.65 \%$ & 30986 & طلاق أو ترمل \\
\hline $62.5 \%$ & 1071518 & $27.5 \%$ & 640245 & $35.85 \%$ & 1711763 & مرافق \\
\hline $35.59 \%$ & 157592 & $64.41 \%$ & 285194 & $9.3 \%$ & 442786 & أخرى \\
\hline $51.23 \%$ & 2445561 & $48.77 \%$ & 2327921 & $100 \%$ & 4773482 & جملة \\
\hline
\end{tabular}

"المصدر :الكتاب الإحصائى السنوى سنة 2016 الأرقام وفقا للنتائج النهائية لتعداد2006

\section{ب- الكجرة بسبب الزواج:}

يمثل هذا الدافع المرتبة الثانية، ولا يقل أهمية عن السبب الأول على الرغم من اختلاف شدته وتفاوتها، لكنه يبقى سبب ودافعًا لما نسبته 28.79\% من المهاجرين. وتأثير هذا النوع من الهجرة أكبر علي الإناث منه على الذكور وتؤكد بيانات جدول رقم (2) أن نسبة المهاجرين تحت تأثير هذا العامل كانت لدى الذكور منهم 20.79\% مقابل \% 79.21

\section{ج- الهجرة بسب الحصول على عمل (بسب وجود فرصة عمل أفضل):}

يؤثر هذا السبب ذو الطبيعة الاقتصادية وبنسبة ليست بالقليلة على الهجرة. إذ أن معطيات جدول رقم (2) تؤكد أن 23.21\% من المهاجرين أقدما على اتخاذ قرار الهجرة تحت تأثير هذا العامل. وهي على عكس السبب الأول، تعد هجرة ذات أهمية أكثر للذكور منها للإناث (93.89\% للذكور مقابل 6.11\% للإناث). 


\section{د - الالتحاق بالتعليم:}

وهذا النوع من الهجرة ذو تأثير أكبر علي الذكور منه على الإناث وتؤكد بيانات جدول رقم

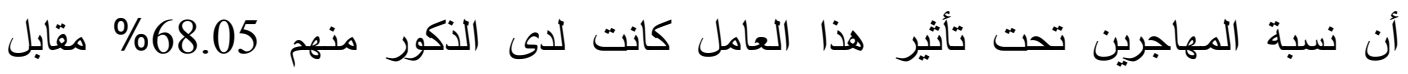

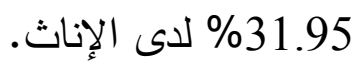

ومن كل ما تقدم يمكننا القول أن ظاهرة الهجرة الداخلية معقدة وتحدث تحت تأثير عدد من

$$
\text { الأسباب التى يمكن حصرها في مجموعتين رئيستين: }
$$

الأولى : الأسباب التى تكون إمكانية التحخل فيها والسيطرة عليها من قبل المجتمع قليلة إن لم تكن

$$
\text { معدومة (الزواج - الالتحاق بالأسرة). }
$$

الثانية : أسباب أخرى، على خلاف سابقتها، يمكن للمجتمع التأثير عليها وتوجيهها (العمل، الدخل،

$$
\text { التعليم، ... إلخ). }
$$

وعليه فإن دراسة هذه الظاهرة، بشكلها الصحيح، يجب أن تتطلق من معرفة أسبابها الرئيسية كخطوة أولى، ومن ثم تحليل هذه الأسباب ومعرفة تداخلاتها وتداعياتها.

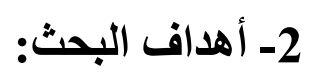

أ- إن الهدف الأساسي للبحث هو استخدام طريقة انحدار الحرف لدراسة تأثير بعض العوامل

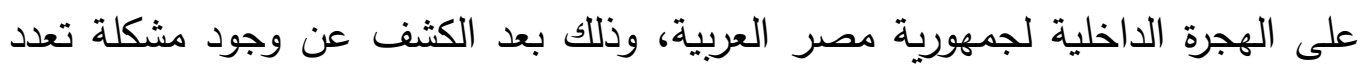
العلاقات الخطية بين المتغيرات التفسيرية، وتطبيق ذلك على بيانات حقيقية تمثل حجم الهجرة الداخلية لجمهورية مصر العربية والعوامل المؤثره عليها خلال الفترة من 1996 إلى لى لكئي

ب-المقارنة بين استخدام طريقة المربعات الصغرى، وطريقة انحدار الحرف، والمفاضلة بين النماذج الدقدرة الناتجة من كلتا الطريقتين وذللك للحصول على أفضل نموذج انحدار خطي متعدد. ت-معرفة مخاطر الهجرة الداخلية على المجتمع المصري كتحدي اجتماعي وثقافي واقتصادي. 
أ- إن استخدام انحدار الحرف للتنبؤ بحجم الهجرة الداخلية لجمهورية مصر العربية يعطي نتائج أفضل من استخدام طريقة المربعات الصغرى. حيث إنه يعالج (يتغلب على) مشكلة الازدواج الخطي (تعدد العلاقات الخطية بين المتغيرات المفسرة). ب- إنه لا توجد فروق ذات دلالة إحصائية بين الفعلي والمقدر من انحدار الحرف. ت- إن انحدار الحرف يساهم في علاج مشكلة الازدواج الخطي بين المتغيرات المفسرة مما يؤدي إلى الوصول إلى نتائج منطقية. ث- أن هناك العديد من المتغيرات التي تؤثر على الهجرة الداخلية. ولكن لتحقيق هدف الدراسة، وهو تحليل أسباب الهجرة الداخلية، سوف يعتمد على العدد الإجمالى للهجرة الداخلية كمتغير تابع، وعلى عدد السكان، وعدد المواليد، وعدد الوفيات، والهجرة الخارجية، كمتغيرات مستقلة. 4- الجانب النظرى للبحث:

يُعد تحليل الانحدار من الطرق الإحصائية المهمة المستخدمة في التعرف على العوامل والمتغيرات المهمة، والمؤثرة في ظاهرة معينة. إذ يوضح العلاقة بين هذه المتغيرات على هيئة معادلة يستدل من تقدير معلماتها على أهمية هذه العلاقة وقوتها واتجاهها، كما يبين تقدير متغير الاستجابة والتنبؤ بما يفيد كثيرًا في التخطيط واتخاذ القرارات الرشيدة. ويتم اختيار طريقة المربعات الصغرى العادية [Cethod Square Med) Ordinary Least)] التي يتم بموجبها اختيار أحسن نموذج مطابق للبيانات، بحيث تجعل مجموع مربعات الخطأ أقل ما يمكن. وتحقق OLS التقدير الجيد Best, Linear Unbiased Estimator) BLUE) إذا تحققت الافتراضات التالية:

$$
\begin{aligned}
& \text { - أن المتغير التفسيري (المستقل) غير عis-stochastic } \\
& \mathrm{E}\left(\varepsilon_{\mathrm{i}}\right)=0 \\
& \text { - أن توقعات عنصر الخطأ = صفر } \\
& \operatorname{var}\left(\varepsilon_{i}\right)=\sigma^{2} \\
& \text { - ثبات تباين عنصر الخطأ (Homoscadasticity) } \\
& \text { - أنه لا يوجد ارتباط ذاتي بين البواقي (No Autocorelations) }
\end{aligned}
$$




$$
\operatorname{cov}\left(\varepsilon_{\mathrm{i}}, \varepsilon_{\mathrm{j}}\right)=0 \quad \mathrm{i} \neq \mathrm{j} \quad-
$$

- أنه لا يوجد تعدد خطي بين المتغيرات المستقلة (Multicollimearity)

$$
\text { (عدم وجود ارتباط خطي بين المتغيرات التوضيحية). }
$$

ولكن في كثير من الأحيان ينتهك واحد أو أكثر من هذه الافتراضات مما يجعل OLS لا لانهين

تحقق التقدير الجيد BLUE مثل مشكلة تعدد العلاقات الخطية التي تئثر على نتائج التقديرات والاختبارات، وتظهر هذه المشكلة نتيجة وجود ارتباط بين المتغيرات التوضيحية (التفسيرية).



من أهم شروط طريقة المربعات الصغرى OLS أن تكون المتغيرات المفسرة غير مرتبطة فيما بينها. وإذا لم يتحقق هذا الفرض أو الشرط يواجه الباحث بما يسمى الازدواج الخطي(تعدد العلاقات الخطية) (Multicollinearity). ونموذج الانحدار الخطي المتعدد عبارة عن انحدار متغير الاستجابة على مجموعة من المتغيرات التوضيحية ويعبر عنها بالعلاقة:

$$
\mathrm{y}_{\mathrm{i}}=\mathrm{B}_{0}+\mathrm{B}_{1} \mathrm{x}_{1 \mathrm{i}}+\mathrm{B}_{2} \mathrm{x}_{2 \mathrm{i}}+\ldots+\mathrm{B}_{\mathrm{p}} \mathrm{x}_{\mathrm{pi}}+\mathrm{e}_{\mathrm{i}}
$$

$$
\text { حيث إن : متغير عشوائي يخضع للتوزيع الطبيعي (بمتوسط } 0 \text { وتباين } \text { o }^{2} \text { ) }
$$
وبصيغة المصفوفات يكتب النموذج بالطريقة الآتية:

$\mathrm{Y}=\mathrm{XB}+\varepsilon$

وعند استخدام طريقة المربعات الصغرى تكون القيمة المقدرة لمعاملات الانحدار B هي: $\hat{\mathrm{B}}=\left(\mathrm{X}^{\prime} \mathrm{X}\right)^{-1} \mathrm{X}^{\prime} \mathrm{Y}$

حيث أن : ميثل متجه المعلمات المقدرة.

وفي حالة وجود علاقة خطية بين بعض المتغيرات التوضيحية فإن: • طريقة المربعات الصغرى تكون ضعيفة. • والقيم المقدرة للمعلمات B غير دقيقة، وربما يكون البعض من إشاراتها سالبا (أو موجبا) بعكس الواقع. 
إن مشكلة (Multicollinearity) توجد في العلاقات الاقتصادية. نظرًا لأن لها تأثيرات خطيرة في دراسة الظاهرة المدروسة، كما أنه من الصعب جداً تجنبها في معظم التطبيقات العملية، هذا بالإضافة إلى أن عدد المعلمات المطلوب تقديرها يكون أقل من حجم العينة قيد البحث أي أن: $\operatorname{Rank}(\mathrm{X})=\mathrm{K}+1<\mathrm{n}$

يعد شرط الرتبة (Rank Condition) أحد الشروط الواجب توفرها في نموذج الانحدار أي أن: $\operatorname{Rank}(\mathrm{X})=\mathrm{n}$

مصفوفة من الرتبة (n*m) لمشاهدات المتغيرات التوضيحية. X وعليه حين تكون المتغيرات التفسيرية (explanatory variables) مستقلة خطيًا (Linearly independent) يكون من الممكن إيجاد معكوس مصفوفة المعلومات (Information Matrix) وبالتالي

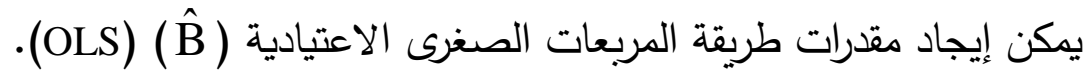
أما إذا كانت هناك علاقة خطية تامة بين اثتتين أو أكثر من المتغيرات التفسيرية فسوف يؤدى الته ذلك إلى انتهاك شرط الرتبة أي أن:

$\operatorname{Rank}(\mathrm{X})<\mathrm{m}$

وعليه فإنه لا يمكن إيجاد معكوس مصفوفة المعلومات (X’X) وبالتالي لا توجد إمكانية لتقدير معلمات النموذج • وهذه الحالة تسمى بالتعدد الخطي التام (Perfect Multicollinearity). ولابد من أجل معالجة هذه المشكلة من حذف المتغيرات التوضيحية المسببة للتعدد الخطي ومن ثم تقدير النموذج.

• أما إذا كان محدد مصفوفة المعلومات لا يساوي الصفر ولكن يكون قريبا منه (أي أن 0 × 1X'X1)، وتظهر هذه الحالة عندما تميل المتغيرات للتحرك سوياً بالزيادة أو النقصان، أو وفق حالة استخدام المتغيرات المرتدة زمنيًا(ذات فترات التأخير) (Lagged variables) ففي لهي هذه الحالة يمكن تقدير معلمات النموذج. ولكن هذه التقديرات سوف تكون غير دقيقة وغير

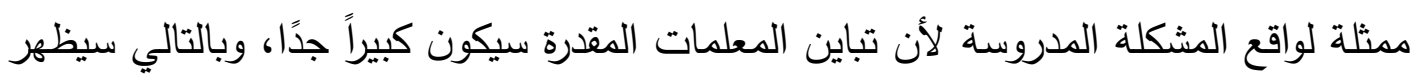


اختبار (t) عدم معنوية المعلمات في حين أنها معنوية في الواقع. ولكن النموذج يعجز عن

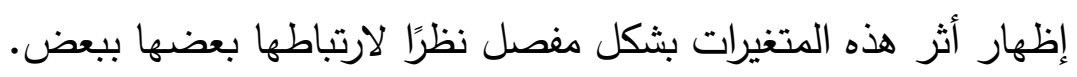
2-4 الكثف عن مشكلة الارتباط الخطي (تثخيص التاخلات الخطية): توجد أساليب عديدة للكثف عن التداخلات الخطية ومنها:

4-2-4-1-1 الارتباط البسيط بين المتغيرات التفسيرية (التوضيحية):

يعد الارتباط البسيط من أبسط مقاييس الكثف عن التداخلات الخطية (الازدواج الخطي)،

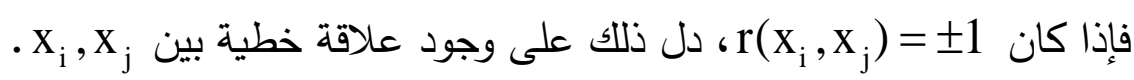
أن مشكلة الازدواج الخطي تحصل عندما تكون rij

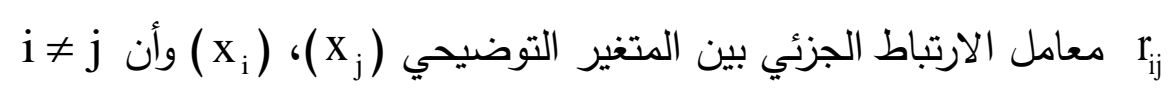

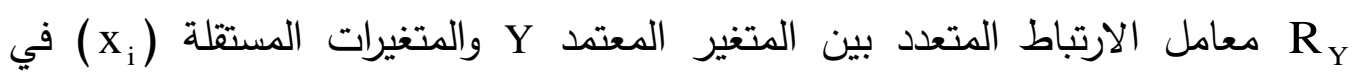
$X^{\prime} X=\left[\begin{array}{cc}1 & r_{12} \\ r_{21} & 1\end{array}\right]$ $\operatorname{vor}\left(b_{1}\right)=\operatorname{var}\left(b_{2}\right)=\frac{\sigma_{e}^{2}}{1-\mathrm{e}^{2}}=\frac{\sigma_{\mathrm{e}}^{2}}{1-\mathrm{r}_{12}^{2}}$

وفي حالة ارتباط أكثر من متغيرين بعلاقة خطية فإنه ليس من الضروري أن يكون

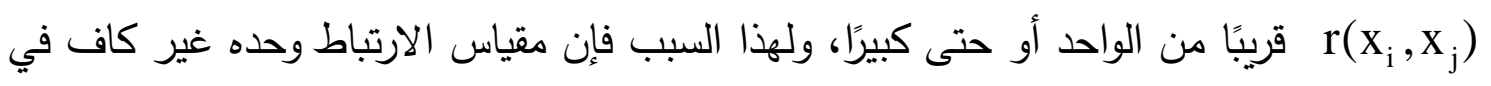
الكثف عن التداخلات الخطية. ويتعين احتساب عوامل تضخم التباين لكل متغير من المتغيرات التوضيحية، حيث يستفاد

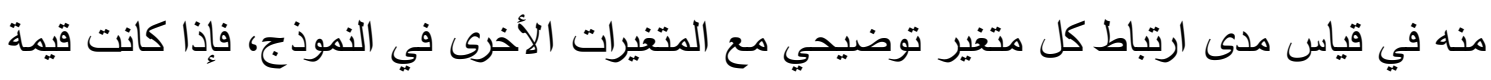
فإنه يدل على أن هناك مشكلة التعدد الخطي بين المتغيرات التوضيحية. وهذا المقدار 
يكون سببًا كافيًا لحذف المتغير X من التحليل أو استخدام طريقة أخرى كبديل عن المربعات الصغرى في التقدير - مان وتستخدم الصيغة الآتية في إيجاد قيمة ( V ) .

$\mathrm{V}_{1} \mathrm{~F}_{\mathrm{j}}=\frac{1}{\left(1-\mathrm{R}_{\mathrm{j}}^{2}\right)} \quad \mathrm{j}=1,2, \ldots, \mathrm{m}$

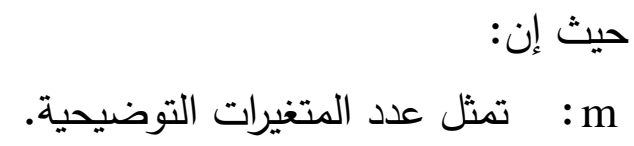

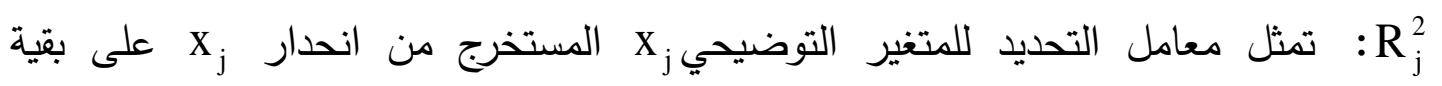
المتغيرات التوضيحية.

2-2-4- اختبار وجود مشكلة التعدد الخطي (الازدو اج الخطي): يشير الازدواج الخطي إلى وجود علاقة خطية بين المتغيرات التفسيرية. هناك عدة اختبارات لاكتشاف وجود الازدواج الخطي واكتشاف المتغيرات المسئولة عنه في النموذج، وأهمها اختبار فارار جلوبر (Farrar Glouber) من أجل اكتشاف وجود هذا الازدواج الخطي واكتشاف نمط هذا الازدواج والمتغيرات المسئولة عنه في

الدالة.

اختبار فار ار - جلوبر:ويتضمن هذا الاختبار ثلاث مستويات • اختبار كا2 أو ل لتحديد مدى ودرجة الازدواج الخطي: ويستخدم لمعرفة ما إذا كان الازدواج الخطي جوهريًا أم لا: ويتم هذا الاختبار كالآتي:

الفرض الأصلي: لا يوجد ازدواج خطي بين المتغيرات المفسرة بمعنى أن تغايرها = صفر . $\mathrm{H}_{0}: \mathrm{X}_{\mathrm{j}}$ orthogonal

$\mathrm{H}_{1}: \mathrm{X}_{\mathrm{j}}$ not orthogonal 
عند غياب العلاقة الخطية بين المتغيرات التوضيحية غيابًا تامًا توصف هذه المتغيرات بأنها متعامدة. ولكن فى أغلب تطبيقات الانحدار تكون المتغيرات التوضيحية غير متعامدة ومرتبطة ارتباطًا قويًا، حيث أنه يصعب تقدير تأثير كل متغير توضيحي تقديرًا منفردًا في النموذج.

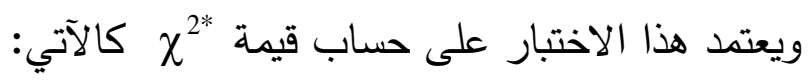
أى يمكن التعبير عن إحصاءة الاختبار رياضيًا كالآتي: $\chi_{c}^{2}=-\left[n-1-\frac{1}{6}(2 k+5) \ln |D|\right]$

$$
\begin{aligned}
& \text { حيث إن: } \\
& \text { n }
\end{aligned}
$$



| $\mathrm{D}=\left[\begin{array}{ccccc}1 & \mathrm{r}_{12} & \mathrm{r}_{13} & \mathrm{~L} & \mathrm{r}_{1 \mathrm{k}} \\ \mathrm{r}_{21} & 1 & \mathrm{r}_{23} & & \mathrm{r}_{2 \mathrm{k}} \\ \mathrm{M} & & & & \\ \mathrm{r}_{\mathrm{k} 1} & \mathrm{r}_{\mathrm{k} 2} & \mathrm{r}_{\mathrm{k} 3} & \mathrm{~L} & 1\end{array}\right]$

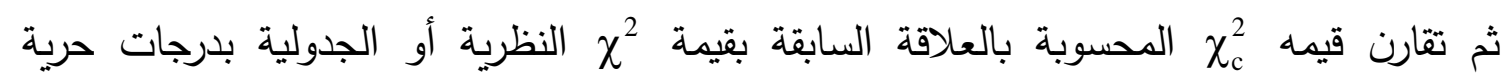
[1/2k(k-1)] ومستوى معنوية معين فإذا كانت: - النظرية جوهري.

2- النظرية • اختبار F لتحديد أي المتغيرات المفسرة أكثر تأثرًا بالازدواج الخطي: وبعد ثبوت مشكلة التعدد الخطي بموجب الاختبار أعلاه، يصبح من الواجب تحديد أي متغير من

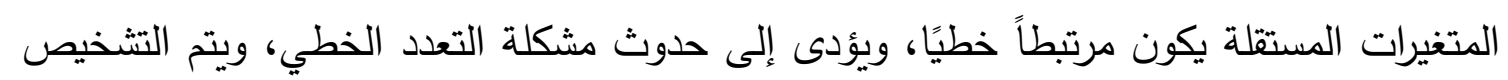
من خلال اختبار F ويحسب بالصيغة الآتية: 
$\mathrm{F}^{*}=\frac{\left(\mathrm{r}_{\mathrm{x}_{\mathrm{i}} \cdot \mathrm{x}_{1} \mathrm{x}_{2} \ldots \mathrm{x}_{\mathrm{k}}}^{2}\right) /(\mathrm{k}-1)}{\left(1-\mathrm{r}_{\mathrm{x}_{\mathrm{i}} \cdot \mathrm{x}_{1} \mathrm{x}_{2} \ldots \mathrm{x}_{\mathrm{k}}}^{2}\right) /(\mathrm{n}-\mathrm{k})}$

حيث إن:

: : $r_{x_{i} \cdot x_{1} x_{2} \ldots x_{k}}^{2}$ حسب اختبار فرضية العدم: $\mathrm{H}_{0}: \mathrm{r}_{\mathrm{x}_{\mathrm{i}} \cdot \mathrm{x}_{1} \mathrm{x}_{2} \ldots \mathrm{x}_{\mathrm{k}}}^{2}=0$

الفرض الأصلي: أن معامل الارتباط المتعدد لا يختلف معنويًا عن الصفر .

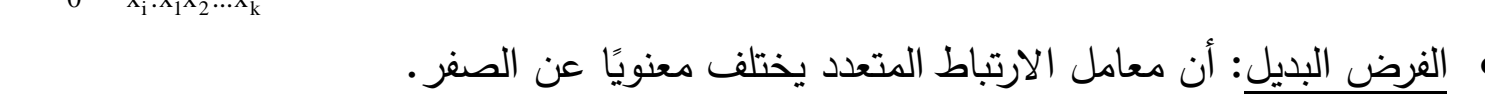
$\mathrm{H}_{1}: \mathrm{r}_{\mathrm{x}_{\mathrm{i}} \cdot \mathrm{x}_{1} \mathrm{x}_{2} \ldots \mathrm{x}_{\mathrm{k}}}^{2} \neq 0$

ثم نقارن قيمة Fc المحسوبة مع قيمة F النظرية أو الجدولية عند مستوى معنوية ودرجات حرية للبسط (k-1) وللمقام (n-k) فإذا كان:

F $>$ F - 1 المتغير X Dتأثر بالازدواج الخطي.

x غير متأثر بالازدواج الخطي، ولا يشكل مصدر قلق لمشكلة الازدواج الخطي. • اختبار t لاكتشاف أي المتغيرات المفسرة يكون مسئولا عن الازدواج الخطي:

بهدف تحديد العوامل المسببة لحصول مثل هذه المشكلة للمتغيرات التفسيرية، يجب إجراء اختبار ثالث، وهو اختبار t الذي يعتمد على قيم معاملات الارتباطات الجزئية ما بين كل اثنين من المتغيرات التفسيرية وبموجب الصيغة الآتية: $\mathrm{t}_{\mathrm{ij}}=\frac{\mathrm{r}_{\mathrm{ij} .12 \ldots \mathrm{k}} \sqrt{\mathrm{n}-\mathrm{k}}}{\sqrt{1-\mathrm{r}_{\mathrm{j} .12 \ldots \mathrm{k}}^{2}}}$

حيث إن: . يمثل مربع معامل الارتباط الجزئي ما بين المتغيرين المفسرين (X) (xi,$\left.x_{j}\right)$ 


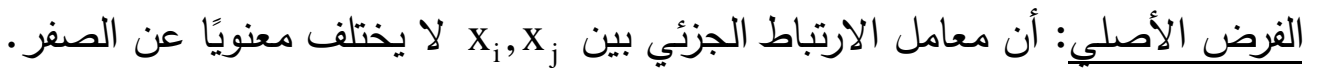

$$
\mathrm{H}_{0}: \mathrm{r}_{\mathrm{ij} .12 \ldots \mathrm{k}}=0
$$

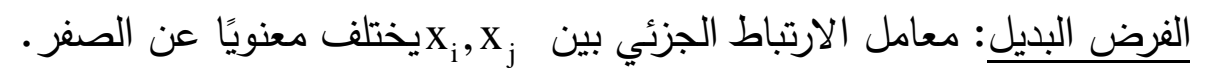

$$
\mathrm{H}_{1}: \mathrm{r}_{\mathrm{ij} .12 \ldots \mathrm{k}} \neq 0
$$

ثم نقارن قيمة th المحسوبة مقابل القيمة الجدولية أو النظرية بدرجات حرية (n-k) ومستوى معنوية معين فإذا كان:

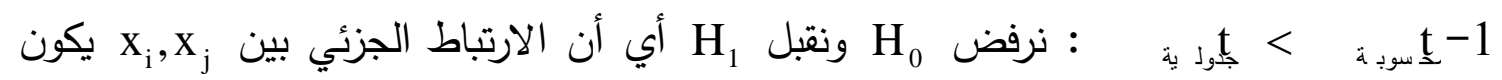

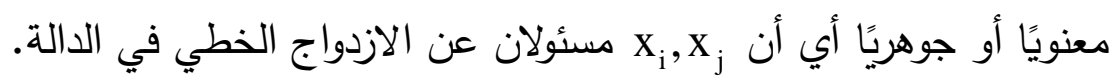
غير معنوي أو

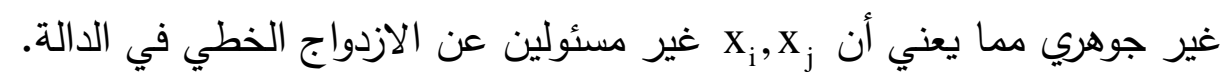

3-4 معالجة مشكلة تعدد العلاقات الخطية:

هناك عدة أساليب يمكن عن طريقها معالجة الازدواج الخطي إن وجد في الدالة، ويتوقف الخفات الأمر على درجة تأثير هذه المشكلة ومدى خطورتها على النموذج المستخدم ونتائجه وهذه

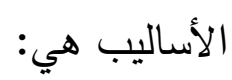

أ- يمكن إهمال مشكلة الازدواج الخطي إذا كان معامل التحديد R أكبر من مربع معامل الارتباط البسيط بين كل زوج من المتغيرات المفسرة بالنموذج.

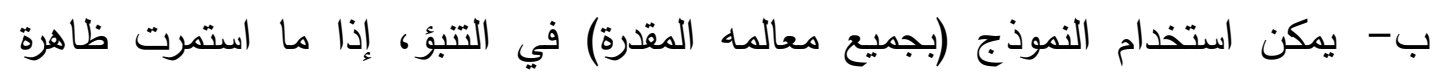

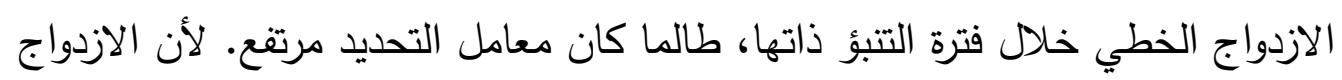
الخطي يعتبر مشكلة فقط إذا كنا نهتم بتقدير معلمات النموذج.

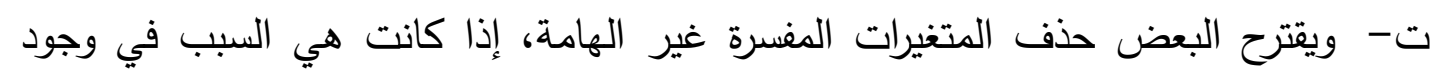

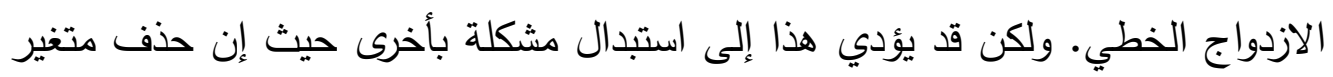

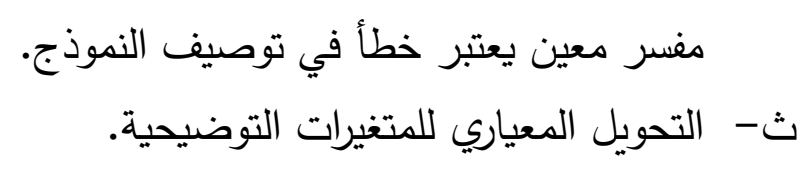


ج-زيادة حجم العينة.

ح-استخدام طرق التقدير التي تعتمد على المعلومات الكمية الاولية ومنها: - مريقة المربعات الصغرى المقيدة. - - طريقة دمج السلاسل الزمنية مع البيانات المقطعية. ج- استخدام الطرق المتحيزة في التقدير، على أمل حل مشكلة الازدواج الخطي، وأهمها: - طريقة الدكونات الرئيسية (Principle Component Analysis). - طريقة انحدار الحرف (Ridge Regression Method). وسيتم الاعتماد في هذا البحث على طريقة انحدار الحرف في تقدير معلمات النماذج.

:Ridge Regression Method 4-4 انحدار الحرف:

يعتبر أسلوب انحدار الحرف (Ridge Regression) أحد بدائل التقدير، عندما تكون هناك مشكلة تعدد خطي (ازدواج خطي) بين المتغيرات التفسيرية (التوضيحية) للنموذج الخطي العام ( و يهدف ذلك إلى معالجة هذه المشكلة. $\mu_{\mathrm{j}} \longrightarrow \mathrm{N}\left(0, \sigma^{2} \mathrm{I}_{\mathrm{n}}\right)$

$\mathrm{E}\left(\mu_{\mathrm{i}}, \mu_{\mathrm{j}}\right) \neq 0$ حيث إن: $\mathrm{E}\left(\mu_{\mathrm{i}} \cdot \mathrm{x}_{\mathrm{i}}\right)=0$

من الملاحظ أنه لدى اتباع هذا الأسلوب، تستخدم الصيغة القياسية للمتغيرات التابعة والمتغيرات التفسيرية، وتجرى جميع الحسابات الخاصة بانحدار الحرف على أساس ذلابك. وبوضع المتغيرات بالصيغة القياسية تتحول المصفوفة (X'X) إلى مصفوفة ارتباط المتغيرات الففسرة (التوضيحية).

وكما هو معلوم يمكن في حالة التعدد الخطي شبه التام، الحصول على مقدرات أولية لمعلمات النموذج الخطي العام من خلال تطبيق (OLS) كالآتي: $b_{L S}=\left(X^{\prime} X\right)^{-1} x^{\prime} y$

$$
\text { وكذللك مصفوفة التباين والتباين الششرك كالآتي: v }
$$


وعند التعويض بقيمة مقدر تباين العينة (Se ${ }^{2}$ نحصل على مصفوفة التباين والتباين المشترك

$\mathrm{v}-\operatorname{cov}\left(\mathrm{b}_{\mathrm{Ls}}\right)=\mathrm{S}_{\mathrm{m}}^{2}\left(\mathrm{x}^{\prime} \mathrm{x}\right)^{-1}$

المقدرة كالآتي:

$\mathrm{E}\left(\mathrm{S}_{\mathrm{e}}^{2}\right)=\sigma_{\mathrm{m}}^{2}$

وتُعد طريقة انحدار الحرف تحسين لطريقة (OLS) عند وجود التعدد الخطي شبه التام، وذلك بإضافة كمية موجبة صغيرة (K) للعناصر القطرية للمصفوفة (X'X) قبل أخذ معكوسها ليصبح $b_{R R}=\left[\begin{array}{r}b_{1 R R} \\ b_{2 R R} \\ M \\ b_{k R R}\end{array}\right]=\left(x^{\prime} x+k I_{n}\right)^{-1} x^{\prime} y$ تقدير المعلمة $\beta$ لنموذج الانحدار بالثكل التالي: لبكيرة حيث إن: (Identity Matrix) : I

إن صيغة التقدير، المعرفة بالمعادلة أعلاه، تعرف بمقدار انحدار الحرف الاعتيادي Ordinary) ويرمزله(ORR)(Re Regression)

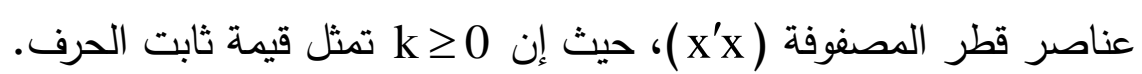

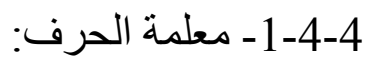

يمكن أن يعرف انحدار الحرف بأنه دالة لمعلمة الحرف k، و k k عدد موجب صغير يضاف إلى القطر الرئيسي للمصفوفة (x'X) بعد ضربه بمصفوفة الوحدة In . ويتم اختيار قيمة

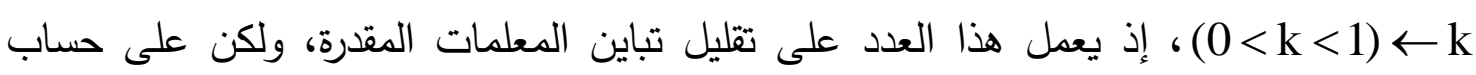
Mean ) (MSE) إدخال بعض التحيز على مقدرات تلك المعلمات. إلا أن متوسط مربعات الخطاين (Square Error الصغرى الاعتيادية. 


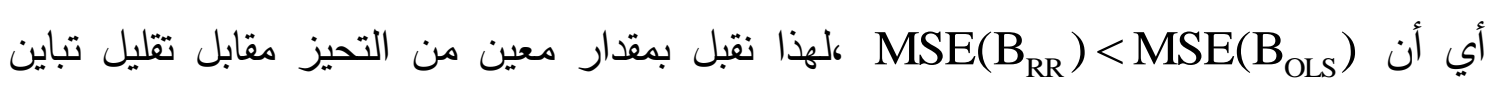
المقدرات. وعندما تكون قيمة kn =kI $=0$ فإن تقديرات طريقة انحدار الحرف تساوي تقديرات طريقة $\hat{B}_{\mathrm{OLS}}=\hat{\mathrm{B}}_{\mathrm{RR}} \quad$ المربعات الصغرى الاعتيادية أي أن:

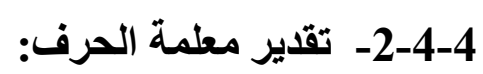

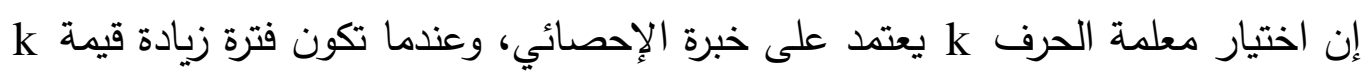
زيادة معقولة وصحيحة وغير سريعة، إذ يكون معنى ذلك تحسنا في المقدرات، وهذا التحسن غالبًا مايستمد من الواقع الذي تكون فيه المقدرات أكثر استقرارًا، أو حين يلاحظ أن هناك تحسنا في التبؤ (عندما k>0) م إذ أن مقدرات انحدار الحرف تميل إلى الاستقرار عند قيمة معينة نسبة

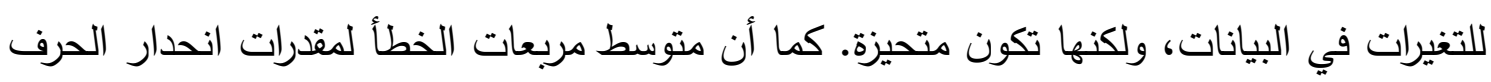
تكون أقل من متوسط مربعات الخطأ لطريقة المربعات الصغرى الاعتيادية أي أن: $\operatorname{MSE}\left(\mathrm{B}_{\mathrm{RR}}\right)<\operatorname{MSE}\left(\mathrm{B}_{\mathrm{OLS}}\right)$

(لهذا نقبل بمقدار معين من التحيز مقابل تقليل تباين المقدرات). وكلما تكبر قيمة k ضمن الفترة (0,1) يقل التباين و تصبح المعلمات أكثر استقرارًا. وتوجد عدة طرق لاختيار معلمة الحرف k منها:

• الطربقة البيانية: وفيها يتم حساب معاملات انحدار الحرف بالاستناد إلى مجموعة من قيم (المناظرة لقيمة k )، ومن ثم رسم معاملات انحدار الحرف مقابل كل قيمة من قيم k . وعليه يتم اختيار قيمة k عند استقرار المعلمات المقدرة وثباتها، على الرغم من اختلاف قيم k.

ويسمى هذا الشكل البياني بـ أثز الحرف "Ridge Trace".

• الطربقة التكرارية: التي تُعد من الطرق المهمة والناجحة لاختيار معلمة الحرف، إذ أنها تتمتع بصغر متوسط مربعات الخطأ مقارنة بالطرق الأخرى. تعتمد الطريقة التكرارية في تقدير معلمة الحرف على قيمة عامل الحرف الابتدائية، وعادة ما يتم في البداية اختيارها مساوية للصفر k وتعويضها في معادلة انحدار الحرف لإيجاد عدة قيم لمقدرات الحرف، ومن ثم الحرص على استقرار هذه المقدرات من خلال أخذ الفرق بين المقدرات 
اللاحقة والسابقة لهذه المقدرات، بعد افتراض خطأ معين يمكن السماح به، ويتم اختيار أحد المقدرات. ويُعد هذا المقدر بمثابة الأفضل، وأن قيمة k المستخدمة هي القيمة المثلى.

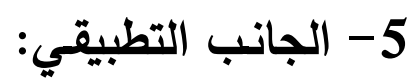

تم تحليل البيانات الخاصة بحجم الهجرة الداخلية في جمهورية مصر العربية للفترة (2015-1996) بإعتبار أنها متغير تابع I(Y) وبإعتبار أن العوامل المؤثرة عليه متغيرات

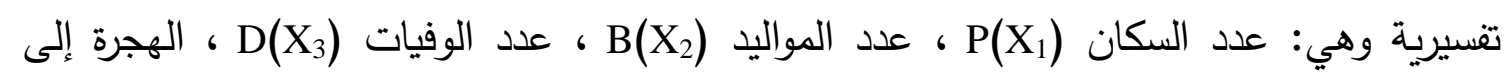
الخارج O(X) ، ميث تم تطبيق نموذج الانحدار الخطي المتعدد: $\mathrm{Y}_{\mathrm{i}}=\beta_{0}+\beta_{1} \mathrm{x}_{1 \mathrm{i}}+\beta_{2} \mathrm{x}_{2 \mathrm{i}}+\ldots+\beta_{\mathrm{R}} \mathrm{x}_{\mathrm{pi}}+\mathrm{e}_{\mathrm{i}}$

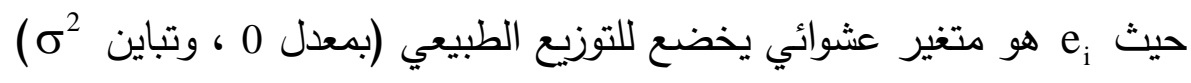
$Y=x \beta+\varepsilon$ وبصيغة المصفوفات يكتب النموذج كالآتى:

وعند استخدام طريقة المربعات الصغرى فإن القيمة المقدرة لمعاملات الانحدار م هي: $\hat{\beta}=\left(x^{\prime} X\right)^{-1} x^{\prime} Y$

حيث أن مر يمثل متجه المعلمات المقدرة.

جدول رقم (3) - جان

بانات الدراسة

\begin{tabular}{|r|r|r|r|r|r|}
\hline year & $\mathrm{I}(\mathrm{Y})^{*}$ & $\mathrm{P}(\mathrm{X} 1)$ & $\mathrm{B}(\mathrm{X} 2)$ & $\mathrm{D}(\mathrm{X} 3)$ & $\mathrm{O}(\mathrm{X} 4)$ \\
\hline 1996 & 1245184 & 58755211 & 1662 & 380 & 1253 \\
\hline 1997 & 1324586 & 60080063 & 1655 & 389 & 1000 \\
\hline 1998 & 1260414 & 61340882 & 1687 & 400 & 882 \\
\hline 1999 & 1297408 & 62638849 & 1693 & 401 & 733 \\
\hline 2000 & 1335118 & 63974724 & 1752 & 405 & 590 \\
\hline 2001 & 1322997 & 65298293 & 1741 & 405 & 764 \\
\hline 2002 & 1328655 & 66627610 & 1767 & 424 & 681 \\
\hline 2003 & 1336459 & 67965096 & 1777 & 440 & 310 \\
\hline 2004 & 1364366 & 69330423 & 1780 & 441 & 378 \\
\hline 2005 & 1322009 & 70653326 & 1801 & 451 & 456 \\
\hline 2006 & 1354569 & 72008901 & 1854 & 452 & 396 \\
\hline 2007 & 1633574 & 73643587 & 1950 & 451 & 387 \\
\hline 2008 & 1548811 & 75193567 & 2051 & 462 & 420 \\
\hline 2009 & 1730110 & 76925139 & 2217 & 477 & 279 \\
\hline 2010 & 1758322 & 78684622 & 2261 & 483 & 617 \\
\hline 2011 & 1843955 & 80530000 & 2442 & 493 & 526 \\
\hline 2012 & 1773410 & 82305000 & 2630 & 530 & 510 \\
\hline 2013 & 2322319 & 84629000 & 2622 & 511 & 430 \\
\hline 2014 & 2183318 & 86814000 & 2720 & 532 & 505 \\
\hline 2015 & 2142430 & 88958000 & 2685 & 574 & 541 \\
\hline & & & & \\
\hline
\end{tabular}

*تم حسابه بطريقة غير مباثرة بمعرفة الباحث حيث أن هذه البيانات غير منشورة بطريقة مبانرة 
وفي حالة وجود علاقة خطية بين بعض المتغيرات التوضيحية تكون طريقة المربعات

الصغرى ضعيفة والقيم المقدرة للمعلمات م غير دقيقة وربما يكون البعض من إثاراتها سالبة (أو موجبة) بعكس الواقع. لذا توجب البحث عن البدائل لهذه الطريقة (مثل استخدام انحدار الحرف). وتم باستخدام البرنامج الإحصائي الجاهز NCSS الحصول على النتائج التي تخص هذه الدراسة وذللك كالآتي: 1-5 طريقة المربعات الصغرى:

تم تطبيق المعادلة (1) لتقدير معلمات النموذج باستخدام طريقة المربعات الصغرى وكما هو مبين في الجدول (4) أدناه:

جدول (4): تقدير الهجرة الداخلية باستخدام طريقة المربعات الصغرى

Regression Coefficients T-Tests

\begin{tabular}{|l|l|l|l|l|l|l|l|}
\hline $\begin{array}{l}\text { Independent } \\
\text { Variable }\end{array}$ & $\begin{array}{l}\text { Regression } \\
\text { Coefficient } \\
\mathrm{b}(\mathrm{i})\end{array}$ & $\begin{array}{l}\text { Standard } \\
\text { Error } \\
\mathrm{Sb}(\mathrm{i})\end{array}$ & $\begin{array}{l}\text { Standard- } \\
\text { ized } \\
\text { Coefficient }\end{array}$ & $\begin{array}{l}\text { T-Statistic } \\
\text { to Test } \\
\mathrm{H0}: \beta(\mathrm{i})=0\end{array}$ & $\begin{array}{l}\text { Prob } \\
\text { Level }\end{array}$ & $\begin{array}{l}\text { Reject } \\
\text { H0 at } \\
5 \% ?\end{array}$ & $\begin{array}{l}\text { Power } \\
\text { of Test } \\
\text { at 5\% }\end{array}$ \\
\hline Intercept & -323958.7 & 531813.5 & 0.0000 & -0.609 & 0.5515 & No & 0.0881 \\
\hline X1 & 0.03993239 & 0.01870709 & 1.0876 & 2.135 & 0.0497 & Yes & 0.5149 \\
\hline X2 & 635.2224 & 289.7372 & 0.7255 & 2.192 & 0.0445 & Yes & 0.5364 \\
\hline X3 & -5186.028 & 2272.043 & -0.8184 & -2.283 & 0.0375 & Yes & 0.5696 \\
\hline X4 & 125.6963 & 162.6888 & 0.0913 & 0.773 & 0.4518 & No & 0.1119 \\
\hline
\end{tabular}

جدول (5): جدول تحليل التباين

Analysis of Variance

\begin{tabular}{|l|l|l|l|l|l|l|l|}
\hline Source & DF & $\begin{array}{l}\mathrm{R}^{2} \text { Lost If } \\
\text { Term(s) } \\
\text { Removed }\end{array}$ & $\begin{array}{l}\text { Sum of } \\
\text { Squares }\end{array}$ & Mean Square & F-Ratio & $\begin{array}{l}\text { Prob } \\
\text { Level }\end{array}$ & Power(5\%) \\
\hline Intercept & 1 & & $4.9386 \mathrm{E}+13$ & $4.9386 \mathrm{E}+13$ & & & \\
\hline Model & 4 & 0.9354 & $2.026949 \mathrm{E}+12$ & $5.067371 \mathrm{E}+11$ & 54.333 & 0.0000 & 1.0000 \\
\hline Error & 15 & 0.0646 & $1.398968 \mathrm{E}+11$ & $9.326453 \mathrm{E}+09$ & & & \\
\hline Total(Adjusted) & 19 & & $2.166845 \mathrm{E}+12$ & $1.140445 \mathrm{E}+11$ & & & \\
\hline
\end{tabular}

Estimated Equation وتكون المعادلة المقدرة كالآتي:

$\mathrm{Y}=-323958.653461081+0.0399323846744563 * \mathrm{X} 1+635.22234533283 * \mathrm{X} 2-5186.0280941826 *$ $\mathrm{X} 3+125.696344201747 * \mathrm{X} 4$

وبعد فحص البيانات تبين وجود علاقة خطية بين المتغيرات (التابعة والمستقلة) وذلك من خلال



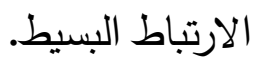


- اختبار وجود مشكلة التعدد الخطي:

يمكن ملاحظة وجود مشكلة التعدد الخطي من استخراج مصفوفة الارتباطات للمتغيرات

التفسيرية حيث تتضح قوة هذه الارتباطاتهمما يعني وجود هذه المشكلة كالآتي: جدول (6): مصفوفة الارتباطات للمتغيرات التوضيحية

Correlation Matrix

\begin{tabular}{|c|c|c|c|c|c|}
\hline & $\mathrm{X} 1$ & $\mathrm{X} 2$ & $\mathrm{X} 3$ & $\mathrm{X} 4$ & $\mathrm{Y}$ \\
\hline $\mathrm{X} 1$ & 1.0000 & 0.9582 & 0.9827 & -0.5964 & 0.9242 \\
\hline $\mathrm{X} 2$ & 0.9582 & 1.0000 & 0.9489 & -0.4059 & 0.9540 \\
\hline $\mathrm{X} 3$ & 0.9827 & 0.9489 & 1.0000 & -0.5638 & 0.8874 \\
\hline $\mathrm{X} 4$ & -0.5964 & -0.4059 & -0.5638 & 1.0000 & -0.3904 \\
\hline $\mathrm{Y}$ & 0.9242 & 0.9540 & 0.8874 & -0.3904 & 1.0000 \\
\hline
\end{tabular}

يلاحظ من خلال مصفوفة الارتباطات (Correlations Matrix) للمتغيرات التوضيحية أن هنالك علاقة قوية جدًا بين المتغيرات (X's) (0.9827)، وهي علاقة طردية بين المتغيرين، وفي المرتبة الثانية كانت العلاقة قوية جدًا أيضًا بين ( إذ بلغ معامل الارتباط بينهما (0.9582)، وهي علاقة طردية بين المتغيرين، وفي المرتبة الثالثة كانت العلاقة قوية أيضًا بين المتغيرين (X2, X3) إذ بلغ معامل الارتباط بينهما (0.9489) وهي علاقة طردية أيضًا.

وهذا يعني وجود مشكلة التعدد الخطي (Multicollinearity problem) بين المتغيرات التوضيحية (X's).

وبما أن هذا المقياس غير كاف لمعرفة تعدد العلاقة الخطية بين المتغيرات، كما تم توضيحه في الجانب النظري، فقد تم الاعتماد على مقياس آخر وهو استخدام مقياس عامل تضخم التباين وكانت النتائج كالآتي:

جدول (7) قيم معامل التضخم في تباينات المعاملات

Least Squares Multicollinearity Section

\begin{tabular}{|c|c|c|c|}
\hline Independent & Variance & R-Squared & \\
\hline Variable & Inflation & Vs Other X's & Tolerance \\
\hline X1 & 60.3163 & 0.9834 & 0.0166 \\
\hline X2 & 25.4422 & 0.9607 & 0.0393 \\
\hline X3 & 29.8651 & 0.9665 & 0.0335 \\
\hline X4 & 3.2441 & 0.6918 & 0.3082 \\
\hline
\end{tabular}

Since some VIF's are greater than 10, multicollinearity is a problem. 
يلاحظ من الجدول المذكور آنفًا (جدول 7) أن VIF للمتغيرات المفسرة X عالية وهذا دليل على أن تلك المتغيرات هي المسببة لتعدد العلاقة، فضلاً عن أنه إذا كانت قيمة أكبر أو تساوي 10 فإن ذلك دليل كاف على كون المتغير يعاني من تضخم في تباين VIF معامله، وأنه مرتبط ببقية المتغيرات التوضيحية. ونظرًا لوجود العلاقة الخطية بين المتغيرات حسب ما تم بيانه في مقاييس اختبار وجود

Ridge ) تعدد العلاقة الخطية بين المتغيرات التوضيحية فقد تم استخدام أسلوب انحدار الحرف (Regression 2-5 استخدام طريقة اتحدار الحرف (Ridge Regression) في تقدير معادلة الهجرة الداخلية: تعتمد هذه الطريقة على تقدير معلمات النموذج عند وجود مشكلة تعدد خطي بين متغيرين توضيحيين، ونظرًا لوجود مشكلة التعدد الخطي بين المتغيرات التوضيحية لدالة الهجرة الداخلية، ولكون أن أحد طرق المعالجة في مثل هذه الحالة هو استخدام طريقة انحدار الحرف لإيجاد مقدرات معلمات النموذج الخطي العام، ولأن هذه الطريقة تعتمد على تحديد قيمة (k) وبما أن هنالك العديد من الطرق لاختيار القيمة الملائمة لـ (k) وأنه ليس هنالك إجماع على طريقة معينة، فقد تم استخدام الطريقة التكرارية.وجدول رقم (8) يوضح معاملات انحدار الحرف القياسي. 
جدول (8) (لانح

معاملات التقاطع لانحدار الحرف القياسي

Standardized Ridge Regression Coefficients Section

\begin{tabular}{|l|l|l|l|l|}
\hline $\mathrm{k}$ & $\mathrm{X} 1$ & $\mathrm{X} 2$ & $\mathrm{X} 3$ & $\mathrm{X} 4$ \\
\hline 0.000000 & 1.0876 & 0.7255 & -0.8184 & 0.0913 \\
\hline 0.000100 & 1.0807 & 0.7265 & -0.8127 & 0.0907 \\
\hline 0.000200 & 1.0738 & 0.7275 & -0.8072 & 0.0902 \\
\hline 0.000300 & 1.0671 & 0.7285 & -0.8017 & 0.0896 \\
\hline 0.000400 & 1.0605 & 0.7294 & -0.7963 & 0.0891 \\
\hline 0.000500 & 1.0540 & 0.7303 & -0.7910 & 0.0886 \\
\hline 0.000600 & 1.0476 & 0.7311 & -0.7857 & 0.0881 \\
\hline 0.000700 & 1.0413 & 0.7319 & -0.7805 & 0.0876 \\
\hline 0.000800 & 1.0352 & 0.7327 & -0.7754 & 0.0871 \\
\hline 0.000900 & 1.0291 & 0.7334 & -0.7703 & 0.0866 \\
\hline 0.001000 & 1.0231 & 0.7341 & -0.7653 & 0.0862 \\
\hline 0.002000 & 0.9683 & 0.7396 & -0.7181 & 0.0822 \\
\hline 0.003000 & 0.9211 & 0.7426 & -0.6759 & 0.0791 \\
\hline 0.004000 & 0.8801 & 0.7439 & -0.6376 & 0.0766 \\
\hline 0.005000 & 0.8441 & 0.7438 & -0.6028 & 0.0747 \\
\hline 0.005000 & 0.8441 & 0.7438 & -0.6028 & 0.0747 \\
\hline 0.006000 & 0.8123 & 0.7427 & -0.5709 & 0.0732 \\
\hline 0.007000 & 0.7840 & 0.7407 & -0.5415 & 0.0720 \\
\hline 0.008000 & 0.7586 & 0.7381 & -0.5143 & 0.0711 \\
\hline 0.009000 & 0.7357 & 0.7351 & -0.4890 & 0.0704 \\
\hline 0.010000 & 0.7150 & 0.7316 & -0.4654 & 0.0699 \\
\hline 0.020000 & 0.5806 & 0.6903 & -0.2932 & 0.0693 \\
\hline 0.030000 & 0.5113 & 0.6508 & -0.1868 & 0.0712 \\
\hline 0.040000 & 0.4688 & 0.6176 & -0.1138 & 0.0728 \\
\hline 0.050000 & 0.4400 & 0.5902 & -0.0603 & 0.0738 \\
\hline 0.060000 & 0.4190 & 0.5672 & -0.0195 & 0.0742 \\
\hline 0.070000 & 0.4029 & 0.5478 & 0.0126 & 0.0741 \\
\hline 0.080000 & 0.3902 & 0.5310 & 0.0385 & 0.0737 \\
\hline 0.090000 & 0.3797 & 0.5165 & 0.0598 & 0.0729 \\
\hline 0.100000 & 0.3710 & 0.5037 & 0.0776 & 0.0719 \\
\hline 0.200000 & 0.3239 & 0.4257 & 0.1644 & 0.0568 \\
\hline 0.205656 & 0.3222 & 0.4227 & 0.1668 & 0.0559 \\
\hline 0.300000 & 0.3011 & 0.3845 & 0.1923 & 0.0412 \\
\hline 0.400000 & 0.2854 & 0.3566 & 0.2031 & 0.0279 \\
\hline 0.500000 & 0.2731 & 0.3352 & 0.2070 & 0.0168 \\
\hline 0.600000 & 0.2626 & 0.3179 & 0.2075 & 0.0076 \\
\hline 0.700000 & 0.2535 & 0.3032 & 0.2062 & 0.0001 \\
\hline 0.800000 & 0.2454 & 0.2905 & 0.2040 & -0.0062 \\
\hline 0.900000 & 0.2380 & 0.2792 & 0.2011 & -0.0115 \\
\hline 1.000000 & 0.2311 & 0.2691 & 0.1980 & -0.0159 \\
\hline & & & & \\
\hline
\end{tabular}

Standardized ridge regression) ويلاحظ أنه من خلال معاملات انحدار الحرف القياسي

(جدficients) (جدل رقم 8)، أتضح أن قيمة k التي من المككن أن تزيل مشكلة الارتباط الخطي 
المتعدد، تتحقق عندما "(k = 0.005)" حيث أن هذه القيمة تكررت مرتين في الجدول (8) وقد بلغت معاملات الاتحدار القياسية (0.0747 , 0.6028 , 0.7438 , 0.8441) على التوالي. ومن استخراج عامل التقاطع لتضخم التباين كما في جدول (9) يلاحظ وضوح المشكلة.

جدول (9) عامل التقاطع لتضخم التباين

\begin{tabular}{|c|c|c|c|c|}
\hline \multicolumn{5}{|c|}{ Variance Inflation Factor Section } \\
\hline $\mathrm{k}$ & $\mathrm{X} 1$ & $\mathrm{X} 2$ & X3 & $\mathrm{X} 4$ \\
\hline 0.000000 & 60.3163 & 25.4422 & 29.8651 & 3.2441 \\
\hline 0.000100 & 59.2766 & 25.1607 & 29.5263 & 3.2181 \\
\hline 0.000200 & 58.2636 & 24.8850 & 29.1947 & 3.1927 \\
\hline 0.000300 & 57.2764 & 24.6151 & 28.8700 & 3.1678 \\
\hline 0.000400 & 56.3142 & 24.3507 & 28.5521 & 3.1434 \\
\hline 0.000500 & 55.3760 & 24.0917 & 28.2407 & 3.1196 \\
\hline 0.000600 & 54.4612 & 23.8378 & 27.9356 & 3.0964 \\
\hline 0.000700 & 53.5689 & 23.5891 & 27.6366 & 3.0736 \\
\hline 0.000800 & 52.6984 & 23.3452 & 27.3436 & 3.0513 \\
\hline 0.000900 & 51.8489 & 23.1060 & 27.0564 & 3.0294 \\
\hline 0.001000 & 51.0199 & 22.8715 & 26.7748 & 3.0080 \\
\hline 0.002000 & 43.7219 & 20.7526 & 24.2336 & 2.8164 \\
\hline 0.003000 & 37.8878 & 18.9748 & 22.1062 & 2.6579 \\
\hline 0.004000 & 33.1508 & 17.4608 & 20.2983 & 2.5247 \\
\hline 0.005000 & 29.2520 & 16.1550 & 18.7423 & 2.4112 \\
\hline 0.005000 & 29.2520 & 16.1550 & 18.7423 & 2.4112 \\
\hline 0.006000 & 26.0048 & 15.0168 & 17.3883 & 2.3133 \\
\hline 0.007000 & 23.2717 & 14.0153 & 16.1991 & 2.2280 \\
\hline 0.008000 & 20.9495 & 13.1271 & 15.1460 & 2.1529 \\
\hline 0.009000 & 18.9598 & 12.3338 & 14.2069 & 2.0864 \\
\hline 0.010000 & 17.2421 & 11.6208 & 13.3641 & 2.0269 \\
\hline 0.020000 & 8.0755 & 7.1341 & 8.0891 & 1.6567 \\
\hline 0.030000 & 4.6933 & 4.9384 & 5.5280 & 1.4704 \\
\hline 0.040000 & 3.0825 & 3.6667 & 4.0525 & 1.3534 \\
\hline 0.050000 & 2.1914 & 2.8553 & 3.1151 & 1.2701 \\
\hline 0.060000 & 1.6471 & 2.3029 & 2.4792 & 1.2055 \\
\hline 0.070000 & 1.2903 & 1.9084 & 2.0269 & 1.1526 \\
\hline 0.080000 & 1.0437 & 1.6162 & 1.6931 & 1.1074 \\
\hline 0.090000 & 0.8662 & 1.3931 & 1.4395 & 1.0677 \\
\hline 0.100000 & 0.7340 & 1.2188 & 1.2421 & 1.0322 \\
\hline 0.200000 & 0.2678 & 0.5137 & 0.4625 & 0.7866 \\
\hline 0.205656 & 0.2584 & 0.4969 & 0.4449 & 0.7762 \\
\hline 0.300000 & 0.1662 & 0.3235 & 0.2679 & 0.6318 \\
\hline 0.400000 & 0.1259 & 0.2389 & 0.1885 & 0.5213 \\
\hline 0.500000 & 0.1046 & 0.1910 & 0.1470 & 0.4386 \\
\hline 0.600000 & 0.0912 & 0.1599 & 0.1219 & 0.3749 \\
\hline 0.700000 & 0.0817 & 0.1380 & 0.1050 & 0.3245 \\
\hline 0.800000 & 0.0746 & 0.1215 & 0.0928 & 0.2840 \\
\hline 0.900000 & 0.0689 & 0.1086 & 0.0835 & 0.2509 \\
\hline 1.000000 & 0.0641 & 0.0982 & 0.0761 & 0.2234 \\
\hline
\end{tabular}




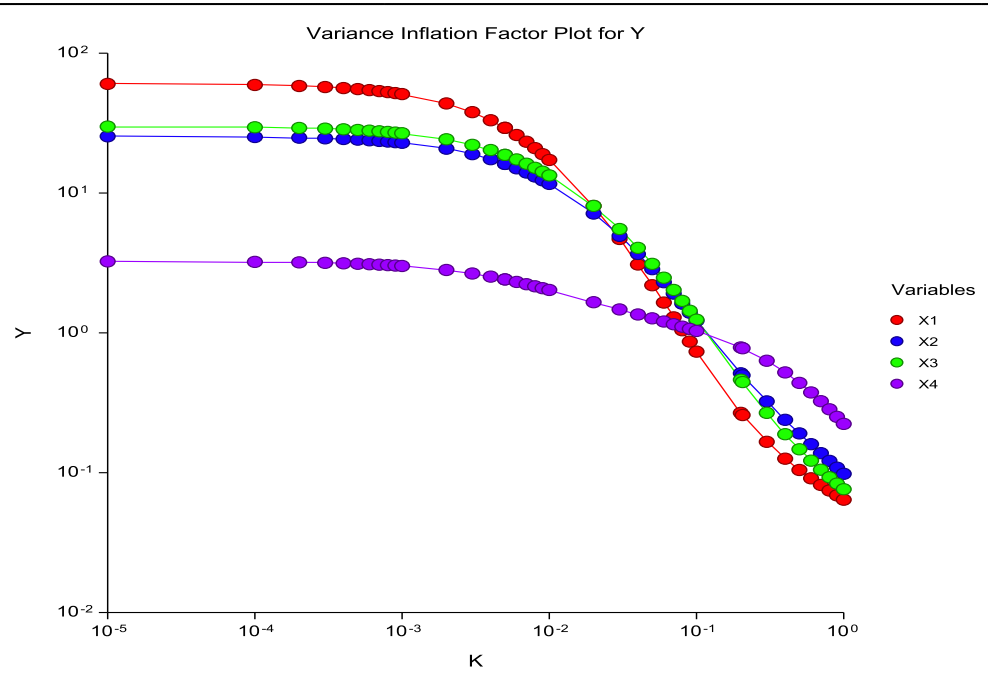

ويمكن أن نلاحظ، من خلال جدول (9) معامل تضخم التباين، أن قيمة k قد بلغت (0.005) بسبب تكرارها ويعد ذلك بمثابة تأكيد للجدول رقم (8) "جدول معاملات انحدار الحرف القياسية" وكان مستوى عامل تضخم التباين بالنسبة للمتغير التوضيحي X1 هو (29.2520)، في حين أن مستوى عامل تضخم التباين بالنسبة للمتغير التوضيحي X2 هو (16.1550). أما مستوى هون عامل التضخم بالنسبة للمتغير التوضيحي X3 فهو (18.7423)، X4 (2.4112) ومن هذا الجدول، يمكن بسهولة تحديد متى يكون VIFs لكل المتغيرات المستقلة أقل من 10. 5-5 مقارنة بين تقدير المربعات الصغزى وتقدير الحرف: بعني

يبين جدول رقم (10) قيم معامل التقاطع، والميل الحدي، والخطأ المعياري، ومعامل التحديد بطريقة التقدير OLS، Ridge وقيمة k = جدول (10)

مقارنة بين طريقة المربعات الصغرى وانحدار الحرف Ridge vs. Least Squares Comparison Section for $\mathrm{k}=0.005000$

\begin{tabular}{|c|c|c|c|c|c|c|}
\hline $\begin{array}{c}\text { Independent } \\
\text { Variable }\end{array}$ & $\begin{array}{c}\text { Regular } \\
\text { Ridge } \\
\text { Coeff's }\end{array}$ & $\begin{array}{c}\text { Regular } \\
\text { L.S. } \\
\text { Coeff's }\end{array}$ & $\begin{array}{c}\text { Stand'zed } \\
\text { Ridge } \\
\text { Coeff's }\end{array}$ & $\begin{array}{c}\text { Stand'zed } \\
\text { L.S. } \\
\text { Coeff's }\end{array}$ & $\begin{array}{c}\text { Ridge } \\
\text { Standard } \\
\text { Error }\end{array}$ & $\begin{array}{c}\text { L.S. } \\
\text { Standard } \\
\text { Error }\end{array}$ \\
\hline Intercept & -318350.1 & -323958.7 & & & & \\
\hline X1 & 0.03099235 & 0.03993239 & 0.8441 & 1.0876 & 0.01398051 & 0.01870709 \\
\hline X2 & 651.2484 & 635.2224 & 0.7438 & 0.7255 & 247.7631 & 289.7372 \\
\hline X3 & -3820.019 & -5186.028 & -0.6028 & -0.8184 & 1931.53 & 2272.043 \\
\hline X4 & 102.8142 & 125.6963 & 0.0747 & 0.0913 & 150.5147 & 162.6888 \\
\hline R-Squared & 0.9256 & 0.9354 & & & & \\
\hline Sigma & 103636.8109 & 96573.5615 & & & & \\
\hline
\end{tabular}




$$
\text { ويلاحظ من خلال جدول رقم (10) أن: }
$$

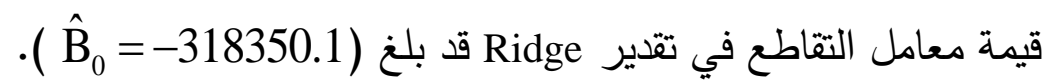

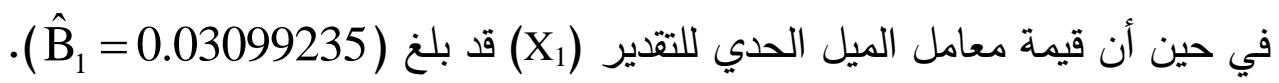



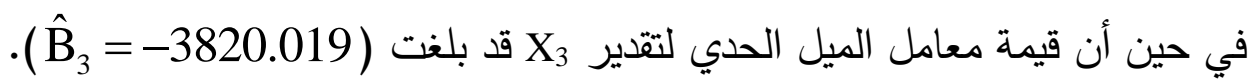

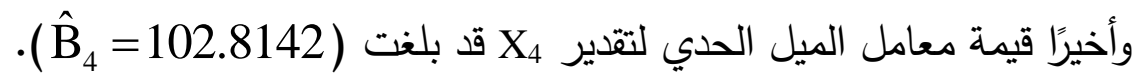
في حين كانت تقديرات OLS هي:

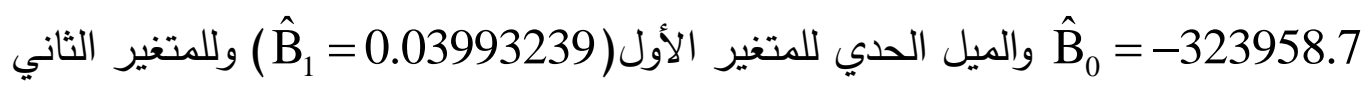
( $\left.\hat{B}_{2}=635.2224\right)$

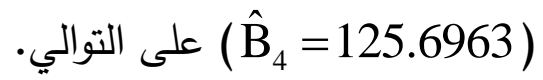

ويلاحظ من الجدول أيضًا أن قيمة الخطأ المعياري لتقدير Ridge بالنسبة للمتغير الأول

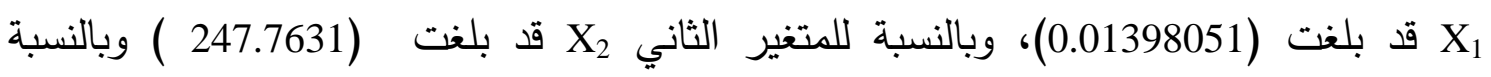



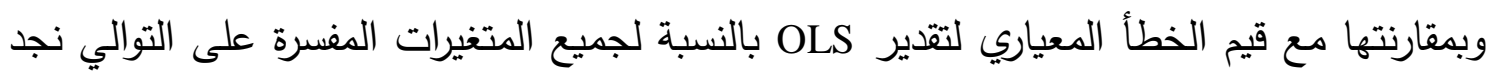

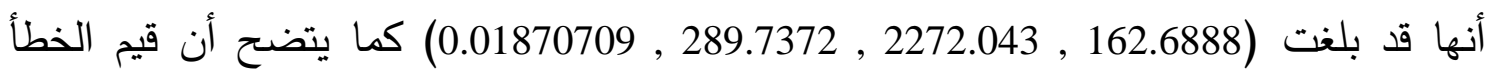
المعياري عند استخدام طريقة تقدير "Ridge" هى أفضل وأقل من قيم الخطأ المعياري عند استخدام

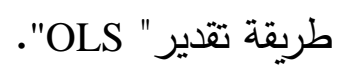
مما يعني أن طريقة Ridge تقلل وتزيل مشكلة التعدد الخطي الموجود بين المتغيرات



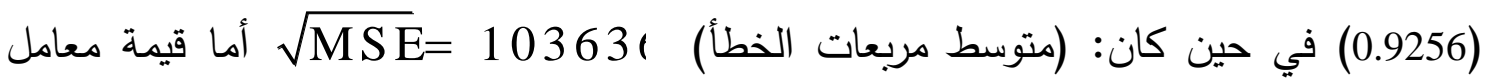

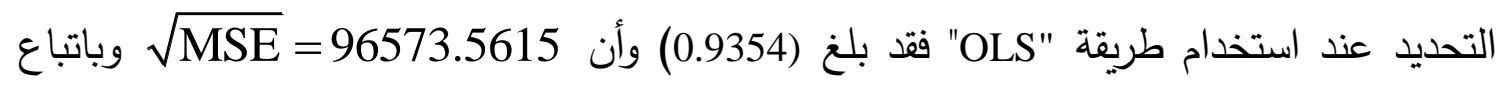

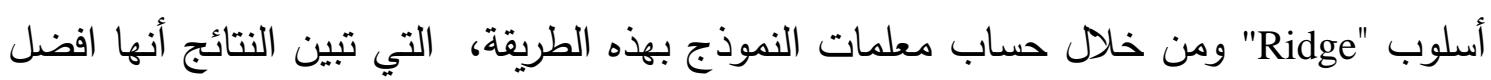


Model $\hat{\mathrm{Y}}=-318350.1+0.03099235 * \mathrm{X} 1+651.2484 * \mathrm{X} 2-3820.019 * \mathrm{X} 3+102.8142 * \mathrm{X} 4$ 37 
أما جدول تحليل التباين للنموذج فهو كالآتي:

جدول (11)

جدول تحليل التباين

Analysis of Variance Section for $\mathrm{k}=0.005000$

\begin{tabular}{|l|l|l|l|l|l|}
\hline Source & DF & $\begin{array}{l}\text { Sum of } \\
\text { Squares }\end{array}$ & $\begin{array}{l}\text { Mean } \\
\text { Square }\end{array}$ & F-Ratio & $\begin{array}{l}\text { Prob } \\
\text { Level }\end{array}$ \\
\hline Intercept & 1 & $4.9386 \mathrm{E}+13$ & $4.9386 \mathrm{E}+13$ & & \\
\hline Model & 4 & $2.005736 \mathrm{E}+12$ & $5.014341 \mathrm{E}+11$ & 46.6859 & 0.000000 \\
\hline Error & 15 & $1.611088 \mathrm{E}+11$ & $1.074059 \mathrm{E}+10$ & & \\
\hline Total(Adjusted) & 19 & $2.166845 \mathrm{E}+12$ & $1.140445 \mathrm{E}+11$ & & \\
\hline
\end{tabular}

Mean of Dependent

Root Mean Square Error

R-Squared

Coefficient of Variation
1571401

103636.8

0.9256

0.06595187

ومن خلال جدول (11) (جدول تحليل التباين) يلاحظ أنه عند استخدام طريقة




أهمية، وضرورية في النموذج، وأن هذا النموذج هو الأفضل.

جدول (12)

حساب المرونات للمتغيرات المستقلة

\begin{tabular}{|c|c|c|c|c|c|}
\hline$\left(\mathrm{X}_{4}\right)$ & $\left(\mathrm{X}_{3}\right)$ & $\left(\mathrm{X}_{2}\right)$ & $\left(\mathrm{X}_{1}\right)$ & $(\mathrm{Y})$ & المتغير \\
\hline 11658 & 9101 & 40747 & 1446356293 & 31428014 & المجموع \\
\hline 582.9 & 455.05 & 2037.35 & 72317814.7 & 1571401 & الو سط الحسابى \\
\hline 0.000371 & 0.00029 & 0.001297 & 46.0212438 & ----- & $\bar{x}_{/ \bar{y}_{\bar{y}}}$ \\
\hline 0.046626 & -1.501783 & 0.823577 & 1.83762826 & ----- & OLS المرونة \\
\hline 0.038138 & -1.10621 & 0.844356 & 1.42629039 & ----- & Ridgeالمرونة \\
\hline
\end{tabular}

$$
\text { يتضح من جدول (12) الخاص بحساب المرونات للمتغيرات المستقلة مايلى: }
$$

بالنسبة لطريقة انحدار OLS: تبين المرونة أن تغيرا قدره 1\% فى عدد السكان

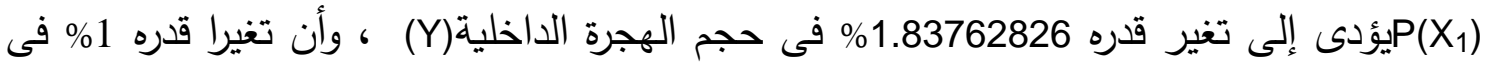

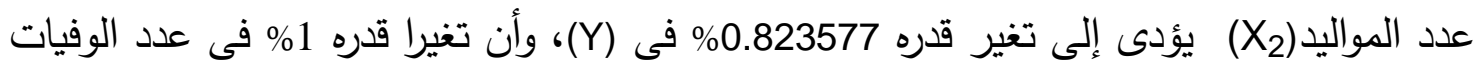
(Xؤدى إلى تغير قدره 1.501783) 
(X) الهجرة الداخلية فى كل حالة. بالنسبة لطريقة انحدار Ridge: تبين المرونة أن تغيرا قدره 1\% فى عدد السكان

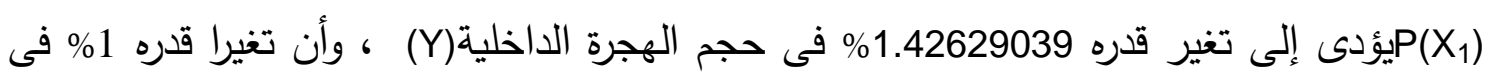

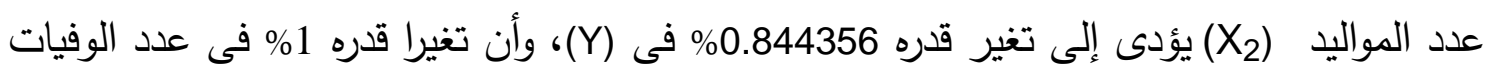

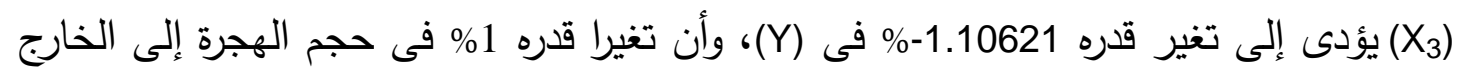
(Xؤدى إلى تغير قدره 038138) الهجرة الداخلية فى كل حالة. ويستفاد من المرونات فى التخطيط الاقتصادى ورسم السياسات، ومن خلال استخدام النموذج الأفضل يمكن استخراج قيم الخطأ والقيم التنبؤية والجدول (13) يوضح ذليطي ذلك.

جدول (13)

القيم التنبؤية

Predicted Values and Residuals Section for $\mathrm{k}=0.005000$

\begin{tabular}{|l|l|l|l|}
\hline Row & Actual $(\mathrm{Y})$ & Predicted $(\hat{\mathrm{Y}})$ & Residual \\
\hline 1 & 1245184 & 1262206 & -17021.85 \\
\hline 2 & 1324586 & 1238315 & 86270.77 \\
\hline 3 & 1260414 & 1244079 & 16335.36 \\
\hline 4 & 1297408 & 1269074 & 28334.15 \\
\hline 5 & 1335118 & 1318917 & 16201.1 \\
\hline 6 & 1322997 & 1370663 & -47666.36 \\
\hline 7 & 1328655 & 1347681 & -19025.54 \\
\hline 8 & 1336459 & 1296381 & 40078.52 \\
\hline 9 & 1364366 & 1343820 & 20545.73 \\
\hline 10 & 1322009 & 1368316 & -46306.68 \\
\hline 11 & 1354569 & 1434855 & -80286.44 \\
\hline 12 & 1633574 & 1550933 & 82641.27 \\
\hline 13 & 1548811 & 1626119 & -77308.01 \\
\hline 14 & 1730110 & 1716095 & 14015.36 \\
\hline 15 & 1758322 & 1811111 & -52789.17 \\
\hline 16 & 1843955 & 1938624 & -94668.45 \\
\hline 17 & 1773410 & 1973084 & -199673.8 \\
\hline 18 & 2322319 & 2104255 & 218063.7 \\
\hline 19 & 2183318 & 2163287 & 20031.4 \\
\hline 20 & 2142430 & 2050201 & 92228.98 \\
\hline
\end{tabular}


شكل رقم (3): طبيعية بواقي التقدير باستخدام طريقة

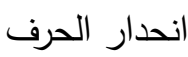

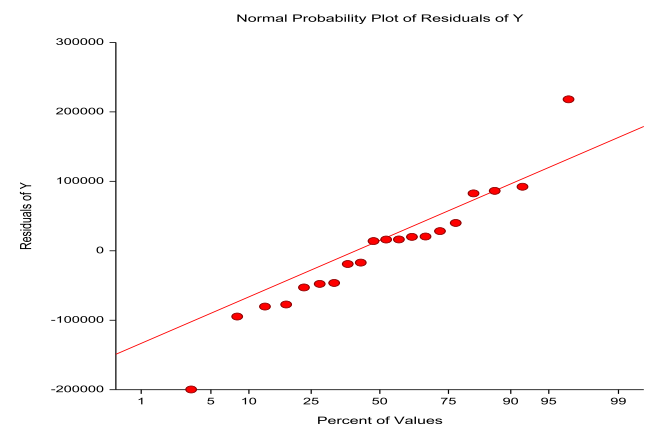

شكل رقم (2): المدرج التكراري لبواقي التقدير

باستخدام طريقة انحدار الحرف

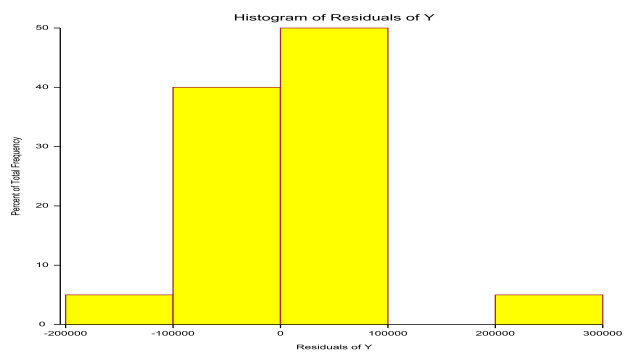

ويمكن أن يعود استخراج القيم التتبؤية (y) للنموذج الأفضل بالفائدة على الباحث الذى يمكنه الاستعانة بهذه القيم المستخرجة لبناء الخطط المستقبلية ولإجراء البحوث. 


\section{6- الاستنتاجـات:}

من خلال إجراء هذه الدراسة تم التوصل إلى مجموعة من الاستتناجات:

ـ أن مشكلة التعدد الخطي تحدث عندما تكون قيمة التباين للمتغيرات التوضيحية كبيرة.

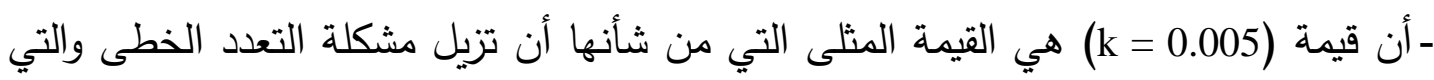

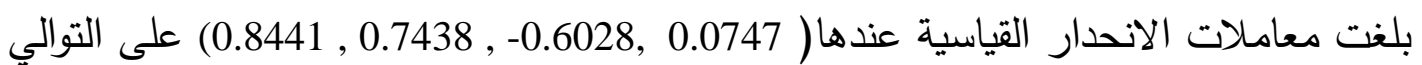

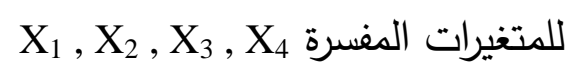

- أن متوسط مربعات الخطأ أفضل معيار للمقارنة. فمن مقارنة طريقة تقدير "Ridge"

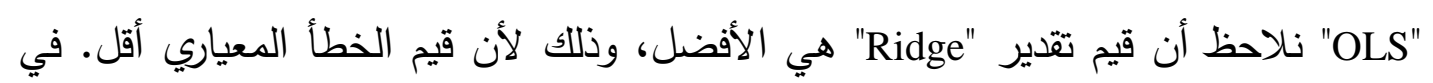

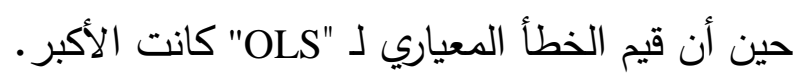
- أن معنوية قيمة F، التي ظهرت في جدول تحليل التباين، تبين أن النموذج المقدر بطريقة " Ridge" ـ أن نموذج الانحدار الخطي المتعدد اعتمادًا على طريقة المربعات الصغرى أعطى نسبة تفسير

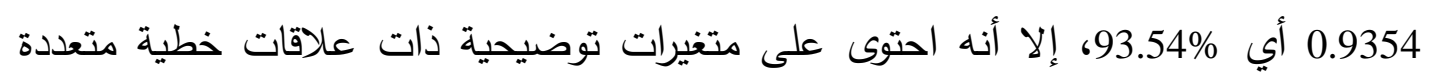
عالية خاصة المتغيرين X أساليب الكشف عن تعدد العلاقات الخطية. - أن ثبات قيم معاملات الانحدار الخطي المتعدد اعتمادًا على طريقة انحدار الحرف عند قيمة


قيم VIF لجميع المتغيرات. إلا أنه توجد نسبة زيادة في متوسط مربعات الخطأ مقدارها

$$
0.07=\frac{103636.8109}{96573.5615}
$$

- بالنسبة للمتغير عدد السكان(X) : تشير تقديرات "OLS" أن له تأثير إيجابى على المتغير

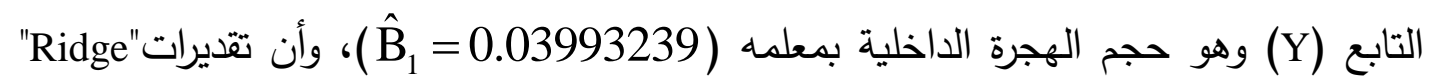

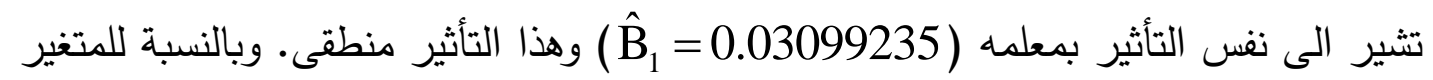

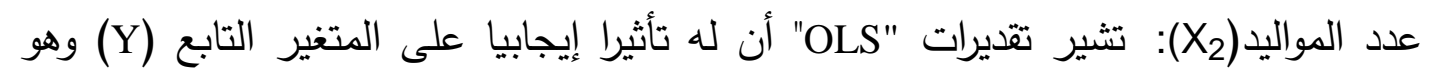


حجم الهجرة الداخلية بمعلمه (B) التأثير بمعلمه (B) $\left(\hat{B}_{2}=651.2484\right)$ وهذا التأثير منطقى. O أما بالنسبة للمتغير عدد الوفيات(X3): تشير تقديرات "OLS" أن له تأثيرا سلبيا على المتغير التابع (Y) وهو حجم الهجرة الداخلية بمعله ( تقديرات"Ridge" تشير الى نفس التأثير بمعله ( وبالنسبة للمتغير حجم الهجرة إلى الخارج (X):): تشير تقديرات "OLS" أن له تأثيرا إيجابيا على المتغير التابع (Y) وهو حجم الهجرة الداخلية بمعله ( تقديرات"Ridge" تشير الى نفس التأثير بمعلمه (

- بملاحظة المرونات للمتغيرات المستقلة اتضح أن ترتيب تأثير المتغيرات على المتغير التابع وهو حجم الهجرة الداخلية من الأكثر إلى الأقل هو كالآتى: عدد السكان (Y) الوفيات (X3) ، ثم يليه عدد المواليد (X2) وأخيرا حجم الهجرة إلى الخارج (X) ) . - وقد اتفقت فى هذا الترتيب كل من طربقة "OLS" وطريقة "Ridge". ويستفاد من هذه المرونات فى التخطيط الاقتصادى ورسم السياسات. ـ أن الهجرة عملية اجتماعية شاملة ومتشابكة في عواملها مع العوامل الاقتصادية، وتتجم عنها آثار على المستوين الاقتصادي والاجتماعي. - أن من الآثار السلبية للهجرة الداخلية: ظهور ظاهرة التحضر الزائف: مجرد التغير في محل الإقامة دون التغير في العادات والتقاليد، ومستوى المعيشة، بإستمرار ممارسة القروين لعاداته التي لا تتفق مع الحياة الحضرية، وتكسس المهاجرين في أحياء مزدحمة تفتقر إلى التخطيط الهندسي. وانتشار العشوائيات، وهي بؤر فاسدة اجتماعيًا وأدت إلى انتشار العديد من الجرائم. وأن المهاجرين أفضل تعليمًا وأصغر سنًا من غير المهاجرين بتلك المناطق مما يعني فقدان تلك المناطق لأكثر الكوادر البشرية قدرة على المساهمة في عملية التتمية. 
- أن الزواج يمثل واحدا من أبرز العوامل الاجتماعية المؤدية إلى الهجرة الداخلية لدى سكان جمهورية مصر العربية، وأن تأثيره على فئة الإناث يكون أكثر من تأثيره على فئة الذكور . - من بين جملة العوامل الاقتصادية المؤدية إلى الهجرة، يعد عامل العمل (عامل تحسين الدخل الفردي) العامل الأهم في تحقيق ذللك. ويكون له تأثير أكبر لدى الذكور عنه لدى الإناث).

\section{7- التوصيـات و المقترحسات:}

- استخدام طريقة انحدار الحرف للتنبؤ بالمتغير المستقل في حالة البيانات الاقتصادية وذلك

$$
\text { لوجود تعدد علاقات خطية بين المتغيرات المستقلة. }
$$

- استخدام أسلوب انحدار الحرف في التقدير ومقارنة النتائج مع طرق التقدير الأخرى مثل

$$
\text { المربعات الصغرى وطريقة الإمكان الأكبر • }
$$

- السعي الدائم في تضييق الفجوة بين الحضر والريف في شتى المجالات لتلافي الآثار السلبية المترتبة على الهجرة الداخلية، وذلك عن طريق تتمية شاملة ومتوازنة في مختلف

$$
\text { محافظات جمهورية مصر العربية وخاصة الآتي: }
$$

• تعميم إلزامية التعليم واستمراريتها، وتطبيق برامج محو الأمية وتطويرها، وتوفير فرص التدريب والتأهيل في مختلف المحافظات ووضع برامج للتدريب وفقًا لمتطلبات هذه المحافظات.

• توفير الخدمات الصحية - الوقائية والعلاجية - وتحسينها وتأمين الرعاية الجيدة للأمومة

$$
\text { والطفولة والأسرة. }
$$

• نشر الوعي السكاني في المناطق الريفية وتحسين نوعية الخدمات الاجتماعية فيها. • إيجاد فرص العمل المناسبة في الريف عن طريق تشجيع الصناعات والحرف الريفية وتطويرها.

• تحسين الظروف السكنية بما يتتاسب مع الخصائص السائدة في كل منطقة وإنشاء المرافق

$$
\text { العامة وتطويرها (كهرباء، مياه، صرف صحي، ... إلخ). }
$$

• تطوير شبكات المواصلات والاتصالات بين مختلف المناطق. 
• إنشاء مشاريع تنموية جديدة تتواكب مع النهضة الاقتصادية كإنشاء مدن صناعية بالقرى، والمدن المتوسطة، وتسهيل القروض الزراعية والصناعية في تلك المناطق أكثر مما فى غيرها من المدن الكبرى.

• يجب أن تتناسب طبيعة كل منطقة وإقليم مع كل مشروع بمعنى أن تتميز كل منطقة بمشاريع تتناسب مع ظروفها وطبيعتها: مناطق سياحية، مناطق تعليمية عالية، مناطق

$$
\text { زراعية، مناطق صناعية. }
$$

إنشاء مركز للتخطيط الحضري والتتمية الريفية يفي باحتياجات كل منطقة. - العمل على تحسين ظروف المرأة ورفع مستويات إسهامها في التتمية الاقتصادية والاجتماعية والثقافية لما في ذلك من أثر في عمليات التحضر والهجرة الداخلية. - ضرورة تبادل الخبرات النظرية والتطبيقية في محاولات لرصد ظاهرة التحضر والهجرة الداخلية ومعالجتها، وخاصة تلك الخبرات المتعلقة بعمليات التعدادات والبحوث والدراسات السكانية. 


\section{1-8 المراجع باللغة العربية:}

- امتثال ميرغني ححمد أحمد طه "معالجة مشكلة التداخل الخطي المتعدد لشركة النيل الأزرق للتغليف والطباعة باستخدام انحدار الحرف (1986-2010)" ماجستير، جامعة السودان للعلوم والتكنولوجيا، كلية الدراسات العليا، كلية العلوم، قسم لإني الإحصاء التطبيقي، فبراير 2014.

- رواء صالح محم "استخدام انحدار الحرف (Ridge) لدراسة أثر بعض العوامل على المؤشر العام لسوق الأوراق المالية"،

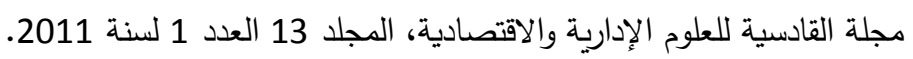
- الكتاب الإحصائي السنوي 2016 الجهاز المركزي للتعبئة العامة والإحصاء. - محاسن صالح الطالب "استخدام أسلوب انحدار الحرف في التتبؤ لتقير نماذج الصندوق الأسود مع التطبيق" المجلة العراقية للعلوم الإحصائية (22) صدصد (121-135)، 2012.

- محمد علي علي أبو سعده "محدات اتجاه الثباب في الأسرة الريغية نحو الهجرة للمناطق الحضرية ببعض قرى محافظة الإنكندرية"، المجلة المصرية للبحوث الزراعة، 93 (1) 2015.

- مروان عبد العزيز دبدوب، أسوان محمد طيب النعيمي "طرائق مقترحة في انحدار الحرف"، المجلة العراقية للعلوم الإحصائية (10) صد صد (85-106)، 2006.

- مزاحم محم يحيى "استخدام المكونات الرئيسية وانحدار الحرف في تقدير معادلة العادية السعر العالمي للقصح للفترة من (1961-

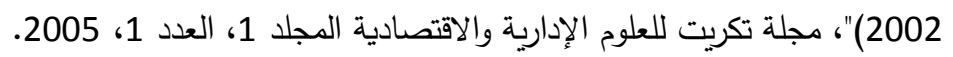
- مصر في أرقام 2017 الجهاز المركزي للتعبئة العامة والإحصاء. - معتز نعيم، مطانيوس مخول "تحليل أسباب الهجرة الداخلية في الجمهورية العربية السورية"، مجلة جامعة دمثق للعلوم الاقتصادية والقانونية، المجلد 21، العدد الأول، 2005.

- موفق إبراهيم حسن "التتبؤ بالعوامل المؤثرة على رأس المال في المملكة الأردنية الهاشمية"، المجلة العراقية للعلوم الإحصائية (25) - 2013، عدد خاص بوقائع المؤتمر العلمي السادس لكلية علومِ الحاسوب والرياضيات. - هيام عبد المجيد حياوي. "تقدير نماذج فضاء الحالة باستخدام أسلوب انحدار الحرف مع التطبيق"، المجلة العراقية للعلوم الإحصائية (18)، 2010.

- هيفاء عبد الجواد سعيد، أحدد نزيه عبد الله الخطيب "حول التوزيع الاحتمالي لعامل الحرف العشوائي يتوفر معلومات

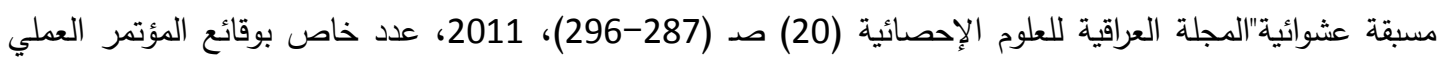
الرابع، كلية علوم الحاسوب والرياضيات.

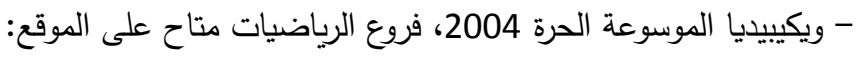

http://ar.wikipedia.org. 


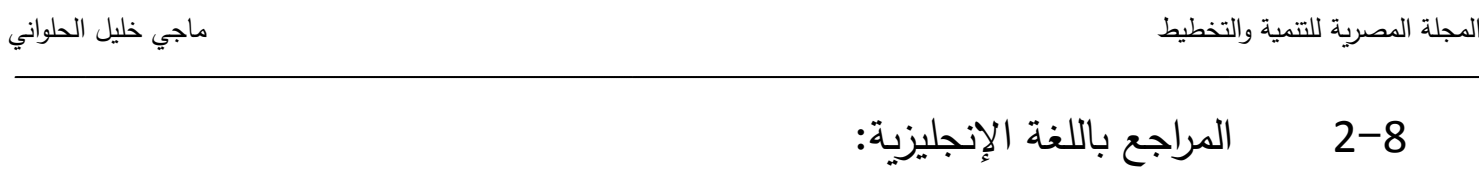

1- Fred L. Ramsey \& Danial W. Schafer. "The Statistical Sleuth A course in Methods of Data Analysis". Third Edition. Brookes / Cole Cengage Learning, 2013.

2- http://www.cscu.cornell.edu.

3- http://www.statisticalassociates.com

4- Michael Berthold, David J. Hand "Intelligent Data Analysis An Introduction," Springer - Verlog Berlin Heidelberge, 1999 New York.

5- NCSS Statistical software. NCSS.com. 335-1.NCSS,LLC. All Rights Reserved. Chapter 335. Chapter 335 "Ridge Regression".

6- William W.S. Wei, "Time Series Analysis: Univeriate and Multivariate Methods", $2^{\text {nd }}$ Edition, Temple University, 2006. 